\title{
Forecasting Macroeconomic Variables using Artificial Neural Network and Traditional Smoothing Techniques
}

\author{
Emrah Önder ${ }^{1}$, Fırat Bayır ${ }^{2}$ and Ali Hepșen ${ }^{3}$
}

\begin{abstract}
For many years, economists have been using statistical tools to estimate parameters of macroeconomic models. Forecasting plays a major role in macroeconomic planning and it is an essential analytical tool in countries' economic strategies. In recent years, researchers are developing new techniques for estimation. Most of these alternative approaches have their origins in the computational intelligence. They have the ability to approximate nonlinear functions, parameters are updated adaptively. In particular, this research focuses on the application of neural networks in modeling and estimation of macroeconomic parameters. Neural networks have received an increasing amount of attention among macroeconomic forecasters because of the ability to approximate any linear and nonlinear relationship with a reasonable degree of accuracy. Turkey is one of the European Union candidate countries such as Iceland, Montenegro, Serbia and The Former Yugoslav Republic of Macedonia. In this study eight macroeconomic indicators including gross domestic product (volume, NGDPD), gross national savings (NGSD_NGDP), inflation (average consumer prices, PCPI), population (LP), total investment (NID_NGDP), unemployment rate (LUR), volume of exports of goods and services (TX_RPCH), volume of imports of goods and services (TM_RPCH) were used for forecasting. As analysis tools, classical time series forecasting methods such as moving averages, exponential smoothing, Brown's single parameter linear exponential smoothing, Brown's second-order exponential smoothing, Holt's two parameter linear exponential smoothing and decomposition methods applied to macroeconomic data. The study focuses mainly on the applicability of artificial neural network model for forecasting macroeconomic parameters in long term and comparing the artificial neural network's results with the Traditional Time Series Analysis (Smoothing \& Decomposition Techniques). To facilitate the presentation, an empirical example is developed to forecast Turkey's eight important macroeconomic parameters. Time Series statistical theory and methods are used to select an adequate technique, based on residual
\end{abstract}

\footnotetext{
1Dr., Istanbul University, School of Business, Department of Quantitative Methods, Istanbul.

${ }^{2}$ Dr., Istanbul University, School of Business, Department of Quantitative Methods, Istanbul.

${ }^{3}$ Assoc.Prof.Dr., Istanbul University, School of Business, Department of Finance, Istanbul.
}

Article Info: Received: May 2, 2013. Revised: May 31, 2013.

Published online : July 1, 2013 
analysis. Turkey will celebrate the 100th anniversary of its foundation in 2023. Policies and implementations targeted for raising economic position.

JEL classification numbers: C53, E00, E27, E29

Keywords: Macro Economic Parameters, Economic Growth, Artificial Neural Network, Forecasting, Smoothing, Decomposition, Time Series, Turkey.

\section{Introduction}

When a country raises her well-being and economic conditions, this increases living standards and social equity in parallel. Also when structural problems of the economy are overcome and significant improvements are achieved in economic indicators such as GDP current prices, inflation and employment than sustainable developments can be obtained. Turkey was in a deep economic crisis in 1994. 1997 Southeast Asia Crisis and 1998 Russia Crisis adversely affected the Turkish economy, and with the earthquakes in 1999 in Marmara region, which has an important share in Turkey's production, the economy narrowed down drastically in 1999. 1990s was a period when Turkey's economy grew less than the potential because of the unstable growth performance, which was recorded as 3.7 percent on average annually. Turkish economy experienced a deep economic crisis at the beginning of $2000 \mathrm{~s}$ as a result of the structural problems in the economy and the weaknesses in the financial sector. GDP growth rate was realized as 6.8 percent during 2002-2007 periods. After the serious global financial crisis in 2009, strong growth trend has maintained again with sound macroeconomic policies and structural reforms and Turkish economy has been one of the fastest growing economies in the world in 2010 and 2011 with 9.2 percent and 8.5 percent growth rates, respectively. In 2001-2005 periods, annual average increase in employment was realized as 0.5 percent and the unemployment rate became 10.6 percent at the end of the period. With the rapid growth and increase in employment in the following period, unemployment rate decreased to 11.9 percent in 2010 and 9.8 percent in 2011. Turkey laid the foundations of long term sustainable development, especially with the structural transformation programs in the economy applied in last decades, and set up resilient conditions for the future generations [1]. The main purpose of "Turkish Exports Strategy for 2023" is to reach 500 billion dollars of exports volume in 2023, the centenary anniversary of the Turkish Republic, with an average of $12 \%$ increase in exports annually. Becoming one of the world's 10 largest economies in 2023 and taking 1,5\% share from the world's trade are also being targeted. Furthermore, it is planned to reach $80 \%$ exports/imports ratio in 2023. "Turkey's Export Strategy for 2023" aims modern and flexible export structure that is based on advanced technology and R\&D (research and development) to respond the demands of today's and future's business environment by modernizing the structure of our exports [2].

Turkey is one of the fastest growing markets in the world with economic growth rates, expanding by 8.5 percent in 2011. Several important economic targets have been mentioned in Turkish government's 2023 economic vision report. These are: taking place among the top 10 economies in the world by the year 2023, reaching a gross domestic product of $\$ 1$ trillion by 2014 , achieving a gross domestic product of $\$ 2$ trillion by 2023 , increasing annual Turkish exports to $\$ 500$ billion, achieving per capita income of 25 
thousand dollars and a foreign trade volume of 1 trillion dollars, increasing employment rate and reducing unemployment rate in Turkey to 5 percent.

Forecasting techniques are important tools in operational management for creating realistic expectations. In literature many different techniques in the area of statistics and artificial intelligence were proposed for achieving close estimations.

[3] used traditional time series analysis and Box Jenkins' models and artificial neural network forecasting method to forecast international tourism arrivals to Turkey for 20082010 based on data period 1986-2007. They found that Winter's seasonal exponential smoothing technique and artificial neural networks are two successful estimator methods for regarding monthly time series data. [4] study was about estimating, evaluating, and selecting among non-linear forecasting models for economic and financial time series. They suggested that careful application of existing techniques, and new models and tests, can result in significant advances in understanding. The objective of [5]'s study (1996) was to provide a practical introductory guide in the design of a neural network for forecasting economic time series data. [6] conducted time series comparisons between the two types of models on the basis of forecast performance and investment return. [7] proposed the use of recurrent neural network in order to forecast foreign exchange rates. He compared three recurrent architectures in terms of prediction accuracy of future forecast for Deutsche mark currency.

[8] applied artificial neural network (ANN) for forecasting government size in Iran. They made comparisons various architectures, transfer functions and learning algorithms on the operation of network. Variables including tax income, oil revenue, population, openness, government expenditure, GDP and GDP per capita were used from 1971-2007 (annually). Their best architecture was a network with two hidden layer and twelve neuron in hidden layers with hyperbolic tangent transfer function. The study of [9] was about demonstrated structural change structural change in macroeconomic time series. They addressed the issue of how time irreversible structures may be generated within the smooth transition processes. They also discussed the link between time irreversibility and loss of uniqueness in the spectral representation of a data generation process. [10] compared the performance of artificial neural networks (ANNs) with exponential smoothing and ARIMA models in forecasting rice exports from Thailand. Their results showed that while the Holt-Winters and the Box-Jenkins models showed satisfactory goodness of fit, the models did not perform as well in predicting unseen data during validation. They also concluded that the ANNs performed relatively well as they were able to track the dynamic non-linear trend and seasonality, and the interactions between them. One of the major drawbacks of ANN is their being black boxes, since it is impossible to solve the relations in their hidden layers of ANN.

\section{Macroeconomic Indicators}

Economists have been using statistical tools to estimate parameters of macroeconomic models. Forecasting plays a major role in macroeconomic planning and it is an essential analytical tool in countries' economic strategies. In this content, the primary purpose of this research is to focus on the application of neural networks in modeling and developing to forecast Turkey's important macroeconomic parameters. Annual time series data are used for the period 1980 to 2012. The sample period is dependent on annual data availability. The data was gathered from the International Monetary Fund world economic 
outlook data base. Our model forecasts eight variables: gross domestic product (GDP), gross national savings, inflation (average consumer prices), population, total investment, unemployment rate, volume of exports of goods and services, volume of imports of goods and services. Gross Domestic Product represents the economic health of a country. It presents a sum of a country's production which consists of all purchases of goods and services produced by a country and services used by individuals, firms, foreigners and the governing bodies. GDP consists of consumer spending, investment expenditure, government spending and net exports hence it portrays an all inclusive picture of an economy because of which it provides an insight to investors which highlights the trend of the economy by comparing GDP levels as an index. GDP is not only used as an indicator for most governments and economic decision-makers for planning and policy formulation; but also it helps the investors to manage their portfolios by providing them with guidance about the state of the economy. On the other hand, it is good measure for an economy and with improvement in research and quality of data, statisticians and governments are trying to find out measures to strengthen GDP and make it a comprehensive indicator of national income.

International standards regarding the compilation of balance of payments statistics are described in the fifth edition of the Balance of Payments Manual prepared by the International Monetary Fund (IMF) in order to provide guidance to member countries. In a general sense, the balance of payments is a statistical statement that systematically records all the economic transactions between residents of a country (Central Government, monetary authority, banks, other sector) and nonresidents for a specific time period. The balance of payments statistics are classified under two major groups: "Current Account" and "Capital and Financial Account". In summary, the current account covers all transactions that involve real sources (including volume of exports and imports of goods and services,) and current transfers; the capital and financial accounts show how these transactions are financed (by means of capital transfer or investment in financial instruments). As mentioned in the European Economic series [11], current account deficits and surpluses are not necessarily macroeconomic imbalances in the sense of developments which are adversely affecting, or have the potential to affect the proper functioning of economies, of the monetary union, or on a wider scale. Deficits and surpluses are a natural consequence of economic interactions between countries. They show to which extent a country relies on borrowing from the rest of the world or how much of its resources it lends abroad. In this way, external borrowing and lending allows countries to trade consumption over time: a country with a current account surplus transfers consumption from today to tomorrow by investing abroad. In turn, a country with a current account deficit can increase its consumption or investment today but must transfer future income abroad to redeem its external debt. Deficits and surpluses can thus simply be the result of an appropriate allocation of savings, taking into account different investment opportunities across countries. Differences in economic prospects lead to differences in saving behavior, with brighter expectations reducing the tendency of economic agents to save and hence contributing to the accumulation of deficits. In particular, countries with a rapidly ageing population may find it opportune to save today to smooth consumption over time. On the other hand, current account deficits and surpluses are part of the adjustment process in a monetary union. They absorb asymmetric shocks in the absence of independent monetary policy and nominal exchange rate adjustment. 
This paper also attempts to analyze the difference between trends of GDP and inflation. It is widely believed that there is a relationship between the two. The problem is that there are disagreements as to what that relationship is or how it operates. As a result, when governments make decisions based on these pieces of information, the outcome often cannot be guaranteed. Exploration of the relationship between GDP and inflation is best begun by developing an understanding of each term individually. As mentioned above, GDP is an acronym for gross domestic product, which is the value of a nation's goods and services during a specified period. This figure is generally regarded as an important indicator of an economy's health. Inflation refers the rate at which the general level of prices for goods and services is rising, and, subsequently, purchasing power is falling.

In determining the economic position of a country is through a comparison of population, national savings and total investments to the gross domestic product of the country. Finally, there is a negative relationship between changes in the rates of GDP growth and unemployment. This long-run relationship between the two economic variables was most famously pointed out in the early 1960s by economist Arthur Okun (known as Okun's Law). According to the principles established by this law, there is a corresponding two percent increase in employment (decrease in unemployment) for every established one percent increase in GDP. The reasoning behind this law is quite simple. It states that GDP levels are driven by the principles of demand and supply, and as such, an increase in demand leads to an increase in GDP. Such an increase in demand must be accompanied by a corresponding increase in productivity and employment to keep up with the demand.

\section{Traditional Time Series Techniques}

In this study two different traditional time series methods including decomposition methods and smoothing methods were applied to the macro economic data for forecasting. The methods and regarding formulas are shown in this section. The notation of [12] is used to explain the time series methods.

\subsection{Decomposition Methods}

Decomposition methods are using for determining secular trend, seasonal variation, conjuncture (cyclical variation) and random fluctuation (irregular variation) components in time series. It this study annual data was used. Therefore 3 important trend function including linear, quadratic and growth were mentioned in this part of this study.

\subsubsection{Least squares method for determining trend}

Least square method is one of the popular methods for determining trend. $\mathrm{X}$ is the time variable (year, month, etc.) in $y_{t}=f(x)$ function. If the sum of the time series variable $(\mathrm{X})$ is identified as zero the estimation values of model parameters can be shown as the following formulas. The trend of $y_{t}$ can be determined by least squares method. It is not very easy to decide which function we should use as a trend. By trying several functions and finding minimum sum of squares of residuals, the suitable trend functions can be found. 
$\sum_{t=1}^{n} e_{t}^{2}=\sum_{t=1}^{n}\left(y_{t}-y_{t}^{\prime}\right)^{2} \Rightarrow \min$

\subsubsection{Linear trend function}

The linear trend function is shown as below:

$$
y=a+b x+e_{t}
$$

When the least squares method is applied the linear trend function, the equations below are obtained.

$$
\sum_{t=1}^{n} e_{t}^{2}=\sum_{t=1}^{n}\left(y_{t}-y_{t}^{\prime}\right)^{2}=\sum_{t=1}^{n}\left(y_{t}-a-b x\right)^{2}
$$

For determining the minimum of this function the first level derivatives should be done regarding to $\mathrm{a}$ and $\mathrm{b}$ parameters.

$$
\begin{aligned}
& \sum y_{t}=n a+b \sum x \\
& \sum x y_{t}=a \sum x+b \sum x^{2}
\end{aligned}
$$

By solving these equations the parameters a and be can be found as follows:

$$
\begin{aligned}
& a=\frac{\sum y_{t}}{n} \\
& b=\frac{\sum x y_{t}}{\sum x^{2}}
\end{aligned}
$$

\subsubsection{Quadratic trend function}

If the observed data has a curved figure (in quadratic trend function the mean of the data is increasing first than start decreasing or reverse) than quadratic trend function can be used.

$$
\begin{aligned}
& y=a+b x+c x^{2}+e_{t} \\
& \sum_{t=1}^{n} e_{t}^{2}=\sum_{t=1}^{n}\left(y_{t}-y_{t}^{\prime}\right)^{2}=\sum_{t=1}^{n}\left(y_{t}-a-b x-c x^{2}\right)^{2}=0
\end{aligned}
$$

First order derivatives of the equation according to $\mathrm{a}, \mathrm{b}$ and $\mathrm{c}$ parameters should be solved for writing the quadratic trend function with using least squares method. The equations below are the normal equations. Three unknown can be found by solving these three equations.

$$
\begin{aligned}
& \sum y_{t}=n a+b \sum x+c \sum x^{2} \\
& \sum x y_{t}=a \sum x+b \sum x^{2}+c \sum x^{3} \\
& \sum x^{2} y_{t}=a \sum x^{2}+b \sum x^{3}+c \sum x^{4}
\end{aligned}
$$




$$
b=\frac{\sum x y_{t}}{\sum x^{2}}
$$

\subsubsection{Growth trend function}

If the change of the y variable is nearly constant in time, growth trend function can be used for this kind of data. The growth trend function is shown below.

$$
\begin{aligned}
& y_{t}=a b^{x}+e_{t} \\
& \sum_{t=1}^{n} e_{t}^{2}=\sum_{t=1}^{n}\left(\log y_{t}-\log y_{t}^{\prime}\right)^{2}=\sum_{t=1}^{n}\left(\log y_{t}-\log a-x \log b\right)^{2}=0 \\
& \sum \log y_{t}=n \log a+\log b \sum x \\
& \sum x \log y_{t}=\log a \sum x+\log b \sum x^{2} \\
& \log a=\frac{\sum \log y_{t}}{n} \\
& \log b=\frac{\sum x \log y_{t}}{\sum x^{2}} \\
& \log y_{t}=\log a+x \log b
\end{aligned}
$$

\subsection{Smoothing Methods}

Random or/and coincidental fluctuations in weekly, monthly, seasonal or annual time series data can be removed or softened by smoothing methods. Six smoothing methods including single moving averages, Brown's simple exponential smoothing method, linear moving averages, Brown's linear exponential smoothing methods with single parameter, Holt's linear exponential smoothing with two parameters and Brown's quadratic exponential smoothing methods are mentioned in this part of the study [12].

\subsubsection{Single moving averages}

Estimation can be done by using arithmetic mean of number of certain $(\mathrm{k})$ prior period of data. Single moving average method gives the same importance level to the past data for estimating future values.

$$
\begin{aligned}
y_{t+1}^{\prime} & =\frac{\left(y_{t}+y_{t-1}+\ldots+y_{t-k+1}\right)}{k} \\
y_{t+1}^{\prime} & =\frac{1}{k} \sum_{i=t-k+1}^{t} y_{i} \\
y_{t+1}^{\prime} & =\frac{y_{t}}{k}-\frac{y_{t-k}}{k}+y_{t}^{\prime}
\end{aligned}
$$




\subsubsection{Brown's simple exponential smoothing method}

It is a suitable method for time series that $y_{1}, y_{2}, \ldots, y_{n}$ has no significant trend or seasonal fluctuations. $y_{t}^{\prime}$ is the estimation value for the time t. $y_{t-1}$ is the observation data for the time t-1. $\alpha$ is a smoothing constant. The constant $\alpha$ has the value between 0 and 1 .

$$
\begin{aligned}
& y_{t}^{\prime}=\alpha y_{t-1}+(1-\alpha) y_{t-1}^{\prime} \\
& y_{t}^{\prime}=y_{t-1}+\alpha\left(y_{t-1}-y_{t-1}^{\prime}\right) \\
& y_{t}^{\prime}=y_{t-1}^{\prime}+\alpha e_{t}
\end{aligned}
$$

\subsubsection{Linear moving averages}

When moving averages method is applied the data which has a significant trend, estimations are always remains lower than actual values. To deal with this situation "Linear Moving Averages" method was developed. The main idea of this method is the calculation of second moving average.

$$
\begin{aligned}
& y_{t}^{\prime}=\frac{y_{t}+y_{t-1}+y_{t-2}+\ldots+y_{t-k+1}}{k} \\
& y_{t}^{\prime \prime}=\frac{y_{t}^{\prime}+y_{t-1}^{\prime}+y_{t-2}^{\prime}+\ldots+y_{t-k+1}^{\prime}}{k} \\
& a_{t}=y_{t}^{\prime}+\left(y^{\prime}-y_{t}^{\prime \prime}\right)=2 y_{t}^{\prime}-y_{t}^{\prime \prime} \\
& b_{t}=\frac{2}{k-1}\left(y_{t}^{\prime}-y_{t}^{\prime \prime}\right) \\
& \hat{y}_{t+m}=a_{t}+b_{t} m
\end{aligned}
$$

The coefficient " $\mathrm{m}$ " is the forecast period to be estimated.

\subsubsection{Brown's linear exponential smoothing method with single parameter}

Brown's Linear Exponential Smoothing Method with single parameter has some similarities with linear moving averages method. But the difference between first and second smoothing values is added into the first smoothing value.

$$
\begin{aligned}
& y_{t}^{\prime}=\alpha y_{t}+(1-\alpha) y_{t-1}^{\prime} \\
& y_{t}^{\prime \prime}=\alpha y_{t}^{\prime}+(1-\alpha) y_{t-1}^{\prime \prime} \\
& a_{t}=y_{t}^{\prime}+\left(y_{t}^{\prime}-y_{t}^{\prime \prime}\right)=2 y_{t}^{\prime}-y_{t}^{\prime \prime} \\
& b_{t}=\frac{\alpha}{1-\alpha}\left(y_{t}^{\prime}-y_{t}^{\prime \prime}\right) \\
& \hat{y}_{t+m}=a_{t}+b_{t} m
\end{aligned}
$$

\subsubsection{Holt's linear exponential smoothing method with two parameters}

It seems similar to previous method (Brown's Linear Exponential Smoothing Method with Single Parameter). But in Holt's Linear Exponential Smoothing Method second 
smoothing is not used. Trend values are smoothed directly. This adds flexibility into the method. The parameters $\alpha$ and $\gamma$ have the values between 0 and 1 .

$$
\begin{aligned}
& y_{t}^{\prime}=\alpha y_{t}+(1-\alpha)\left(y_{t-1}^{\prime}+b_{t-1}\right) \\
& b_{t}=\gamma\left(y_{t}^{\prime}-y_{t-1}^{\prime}\right)+(1-\gamma) b_{t-1} \\
& \hat{y}_{t+m}=y_{t}^{\prime}-b_{t} m
\end{aligned}
$$

The parameters $\alpha$ and $\gamma$ are the smoothing constants. These parameters should be optimized for minimizing the sum of error squares.

\subsubsection{Brown's quadratic exponential smoothing method}

When the time series are curved shape (quadratic, third order or more) Brown's quadratic exponential smoothing technique is suitable for estimation. Third parameter is added to the model. The equations for quadratic exponential smoothing are below:

$$
\begin{aligned}
& y_{t}^{\prime}=\alpha y_{t}+(1-\alpha) y_{t-1}^{\prime} \\
& y_{t}^{\prime \prime}=\alpha y_{t}^{\prime}+(1-\alpha) y_{t-1}^{\prime \prime} \\
& y_{t}^{\prime \prime \prime}=\alpha y_{t}^{\prime \prime}+(1-\alpha) y_{t-1}^{\prime \prime \prime} \\
& a_{t}=3 y_{t}^{\prime}-3 y_{t}^{\prime \prime}+y_{t}^{\prime \prime \prime} \\
& b_{t}=\frac{\alpha}{2(1-\alpha)^{2}}\left[(6-5 \alpha) y_{t}^{\prime}-(10-8 \alpha) y_{t}^{\prime \prime}+(4-3 \alpha) y_{t}^{\prime \prime \prime}\right] \\
& c_{t}=\frac{\alpha^{2}}{(1-\alpha)^{2}}\left(y_{t}^{\prime}-2 y_{t}^{\prime \prime}+y^{\prime \prime \prime}\right)
\end{aligned}
$$

Estimation equation can be shown as below:

$$
\hat{y}_{t+m}=a_{t}+b_{t} m+\frac{1}{2} c_{t} m^{2}
$$

The selection of the $\alpha$ coefficient can be done as the selection in previous methods.

\section{Artificial Neural Networks for Forecasting}

Artificial Neural Networks (ANN) provides a robust approach to approximating and forecasting real, valued and vector-value functions. Under some conditions and for certain types of problems, ANN provides better solutions then traditional statistical methods.

The study of ANNs has been inspired in part by the observation that biological learning systems are built of very complex webs of interconnected neurons. In rough analogy, ANNs are built out of a densely interconnected set of sample units, where each unit takes a number of real-valued inputs (possibly the outputs of other units) and produces a single real-valued output, which may become input to other units [13].

The structure of an artificial network of most commonly used type is the multilayer perceptrons. It consists of several layers of processing units (also termed neurons or 
nodes). The input values (input data) are fed to the neurons in the so-called input layer. The input values are processed within the individual neurons of the input layer and then the output values of these neurons are forwarded to the neurons in the hidden layers. The output of the system, that has target values, is lie on the output layer. The input variables are represent to the independent variables and the output variables are represent to the dependent variables.

Each connection (between neurons) has an associated parameter indicating the strength of this connection, the so-called weight. By changing the weights in a specific manner, the network can learn to map patterns presented at the input layer to target values on the output layer. This description of the procedure, by means of which this weight adaptation is performed, is called learning or training algorithm [14]. There are several learning algorithms in ANN literatures, i.e. Quick Propagation, Conjugate Gradient Descent, Quasi-Newton, Levenberg-Marquardt and Back Propagation.

In learning phase, for each data row, the input values are processed in the input layer then all the information are sent to each of the neurons on the hidden layers, through connections. But in this transmission, data are multiplied by weights of the corresponding connections. Neurons on the hidden layer collect all the information from input layer and by using activation function, neuron produce new data and send it to the next layer, over the connections by multiplying weights. The commonly used activation functions are logistic, linear, hyperbolic tangent, sigmoid. In each iteration, to match the output of the system and output data, weights of the connections are all adjusted in accordance with the error-correction rule. This operation is called learning or training of the network.

Usually, the data available for training the network is divided in two non-overlapping parts: the so-called training and testing sets. The commonly large training set is used to teach the network to desire target function. Then the network is applied to data in the test set in order to available its generalization ability, i.e. the ability to derive correct conclusions about the population properties of the data from the sample properties of the training set. Sometimes the validation set can be used to validate the network after the training phase but before the test phase.

As in most other neural networks applications, data processing -scaling and transformingis important for a good prediction performance of financial time series. The input and output variables must be scaled between the upper and lower bonds of the transfer functions (usually between zero and one minus one and one). Two of the most common data transformations in both traditional and neural network forecasting are first differencing and taking logarithm of a variable. 


\section{Forecasting Results}

\subsection{Results of Smoothing Methods}

\subsubsection{Forecasting results of indicator 1 (Gross Domestic Product, Current Prices)}

Table 1: Selection of Method for Forecasting "Gross Domestic Product, Current Prices"

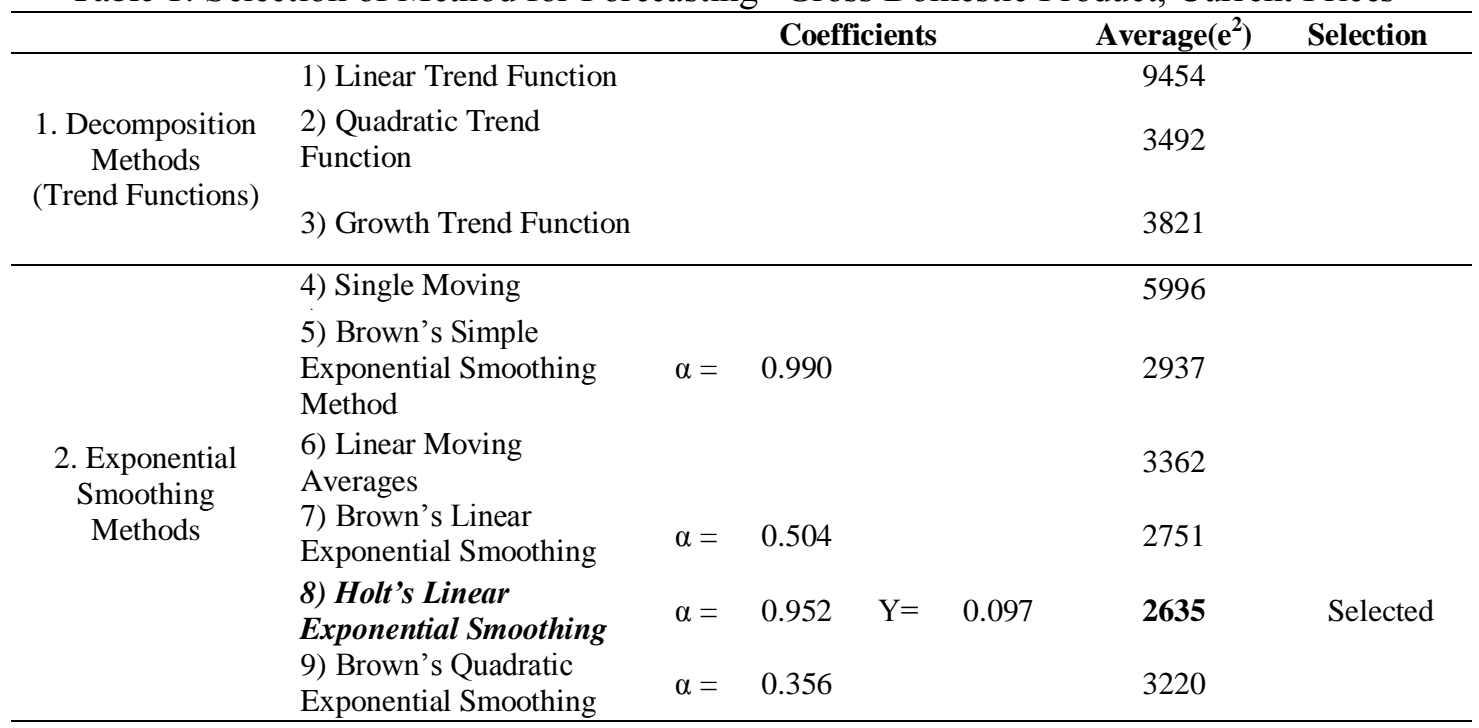

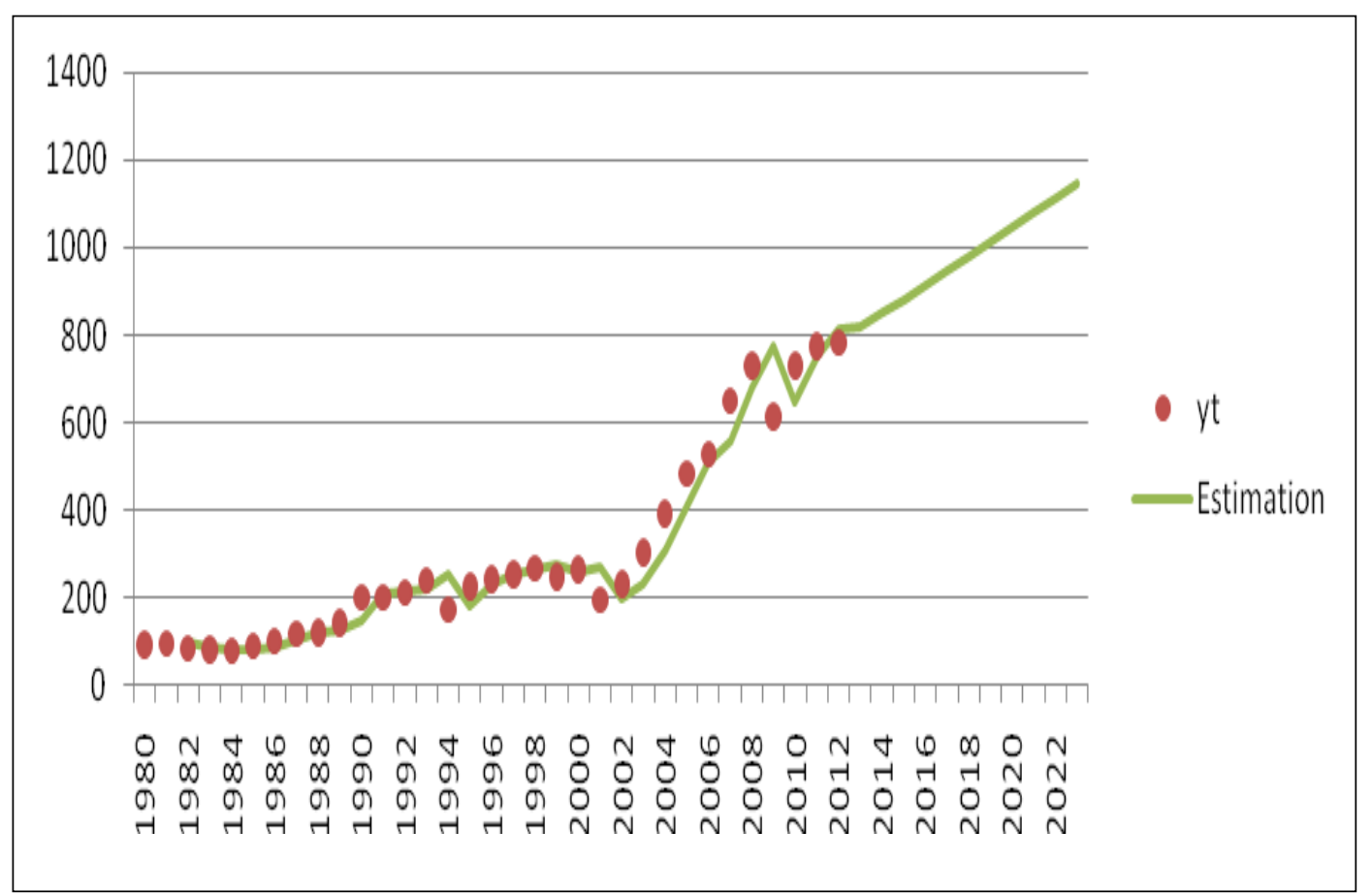

Figure 1: Estimation of "Gross Domestic Product, Current Prices" Data Using Holt's Linear Exponential Smoothing Method 


\subsubsection{Forecasting results of indicator 2 (Total Investment)}

Table 2: Selection of Method for Forecasting "Total Investment"

\begin{tabular}{|c|c|c|c|c|c|c|c|}
\hline & & \multicolumn{4}{|c|}{ Coefficients } & $\operatorname{Average}\left(\mathrm{e}^{2}\right)$ & Selection \\
\hline \multirow{3}{*}{$\begin{array}{l}\text { 1. Decomposition } \\
\text { Methods } \\
\text { (Trend Functions) }\end{array}$} & 1) Linear Trend & & & & & 6.06 & \multirow{3}{*}{ Selected } \\
\hline & $\begin{array}{l}\text { 2) Quadratic Trend } \\
\text { Function }\end{array}$ & & & & & 6.03 & \\
\hline & $\begin{array}{l}\text { 3) Growth Trend } \\
\text { Function }\end{array}$ & & & & & 6.07 & \\
\hline \multirow{6}{*}{$\begin{array}{l}\text { 2. Exponential } \\
\text { Smoothing } \\
\text { Methods }\end{array}$} & 4) Single Moving & & & & & 6.84 & \\
\hline & $\begin{array}{l}\text { 5) Brown's Simple } \\
\text { Exponential Smoothing }\end{array}$ & $\alpha=$ & 0.606 & & & 6.95 & \\
\hline & $\begin{array}{l}\text { 6) Linear Moving } \\
\text { Averages }\end{array}$ & & & & & 11.90 & \\
\hline & $\begin{array}{l}\text { 7) Brown's Linear } \\
\text { Exponential Smoothing } \\
\text { Method }\end{array}$ & $\alpha=$ & 0.209 & \multirow{3}{*}{$Y=$} & \multirow{3}{*}{0.037} & 8.18 & \\
\hline & $\begin{array}{l}\text { 8) Holt's Linear } \\
\text { Exponential Smoothing }\end{array}$ & $\alpha=$ & 0.872 & & & 8.21 & \\
\hline & $\begin{array}{l}\text { 9) Brown's Quadratic } \\
\text { Exponential Smoothing }\end{array}$ & $\alpha=$ & 0.074 & & & 8.58 & \\
\hline
\end{tabular}

Trend Function of "Total Investment": $y=21.1414-0.1346 x+0.0023 x^{2}+e_{t}$

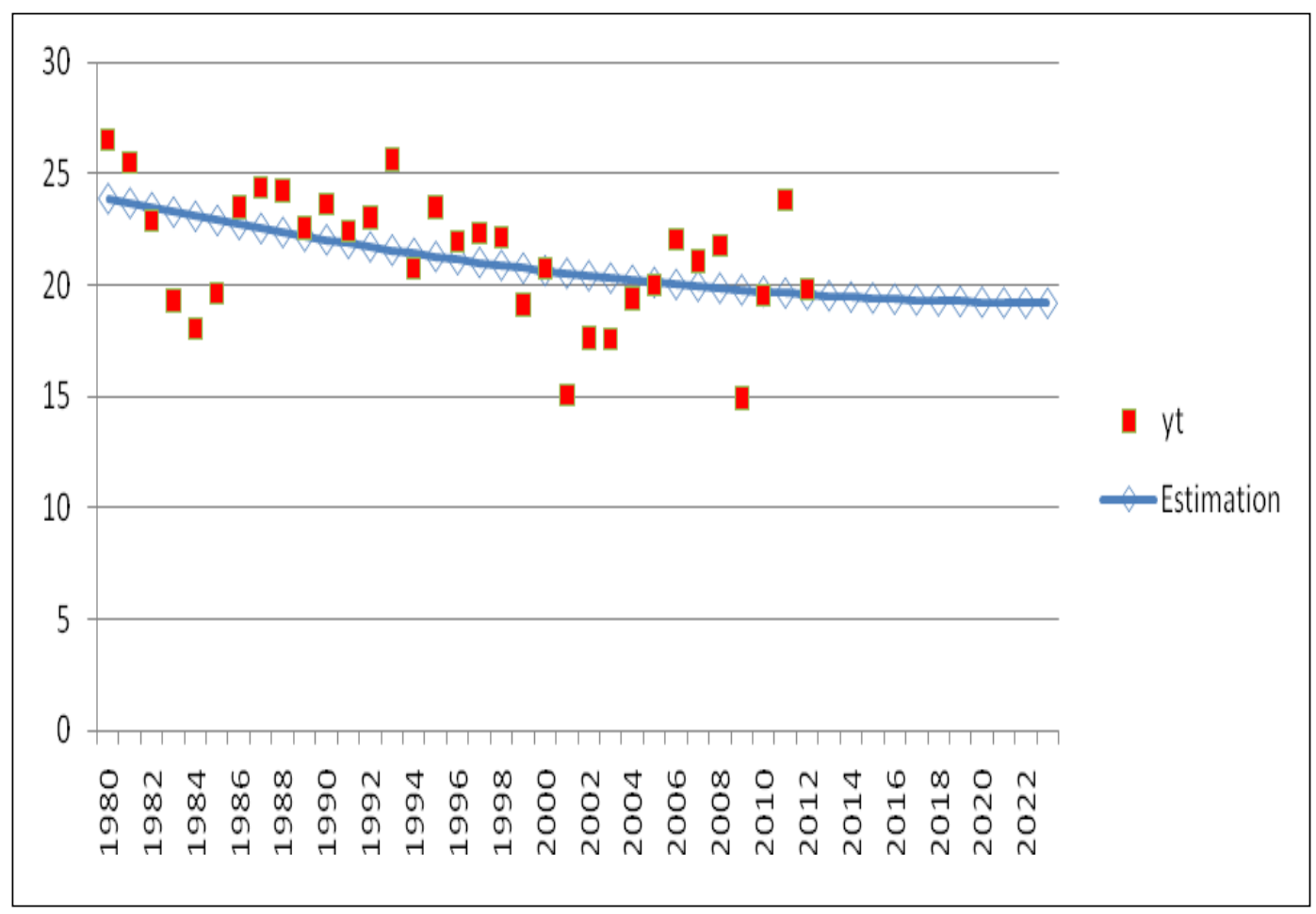

Figure 2: Estimation of “Total Investment” Data Using Decomposition (Quadratic Trend) Method 


\subsubsection{Forecasting results of indicator 3 (Gross National Savings)}

Table 3: Selection of Method for Forecasting "Gross National Savings"

\begin{tabular}{|c|c|c|c|c|c|c|c|}
\hline & & \multicolumn{4}{|c|}{ Coefficients } & $\operatorname{Average}\left(\mathrm{e}^{2}\right)$ & Selection \\
\hline \multirow{3}{*}{$\begin{array}{l}\text { 1. Decomposition } \\
\text { Methods } \\
\text { (Trend } \\
\text { Functions) }\end{array}$} & 1) Linear Trend & & & & & 5.79 & \\
\hline & $\begin{array}{l}\text { 2) Quadratic Trend } \\
\text { Function }\end{array}$ & & & & & 3.91 & \\
\hline & $\begin{array}{l}\text { 3) Growth Trend } \\
\text { Function }\end{array}$ & & & & & 6.45 & \\
\hline \multirow{6}{*}{$\begin{array}{l}\text { 2. Exponential } \\
\text { Smoothing } \\
\text { Methods }\end{array}$} & $\begin{array}{l}\text { 4) Single Moving } \\
\text { Averages }\end{array}$ & & & & & 5.41 & \\
\hline & $\begin{array}{l}\text { 5) Brown's Simple } \\
\text { Exponential Smoothing } \\
\text { Method }\end{array}$ & $\alpha=$ & 0.990 & & & 3.48 & \\
\hline & $\begin{array}{l}\text { 6) Linear Moving } \\
\text { Averages }\end{array}$ & & & & & 7.28 & \\
\hline & $\begin{array}{l}\text { 7) Brown's Linear } \\
\text { Exponential Smoothing }\end{array}$ & $\alpha=$ & 0.638 & \multirow{3}{*}{$\mathrm{Y}=$} & \multirow{3}{*}{0.037} & 4.49 & \multirow{3}{*}{ Selected } \\
\hline & $\begin{array}{l}\text { 8) Holt's Linear } \\
\text { Exponential }\end{array}$ & $\alpha=$ & 0.990 & & & 3.46 & \\
\hline & $\begin{array}{l}\text { 9) Brown s Quadratic } \\
\text { Exponential Smoothing }\end{array}$ & $\alpha=$ & 0.193 & & & 5.52 & \\
\hline
\end{tabular}

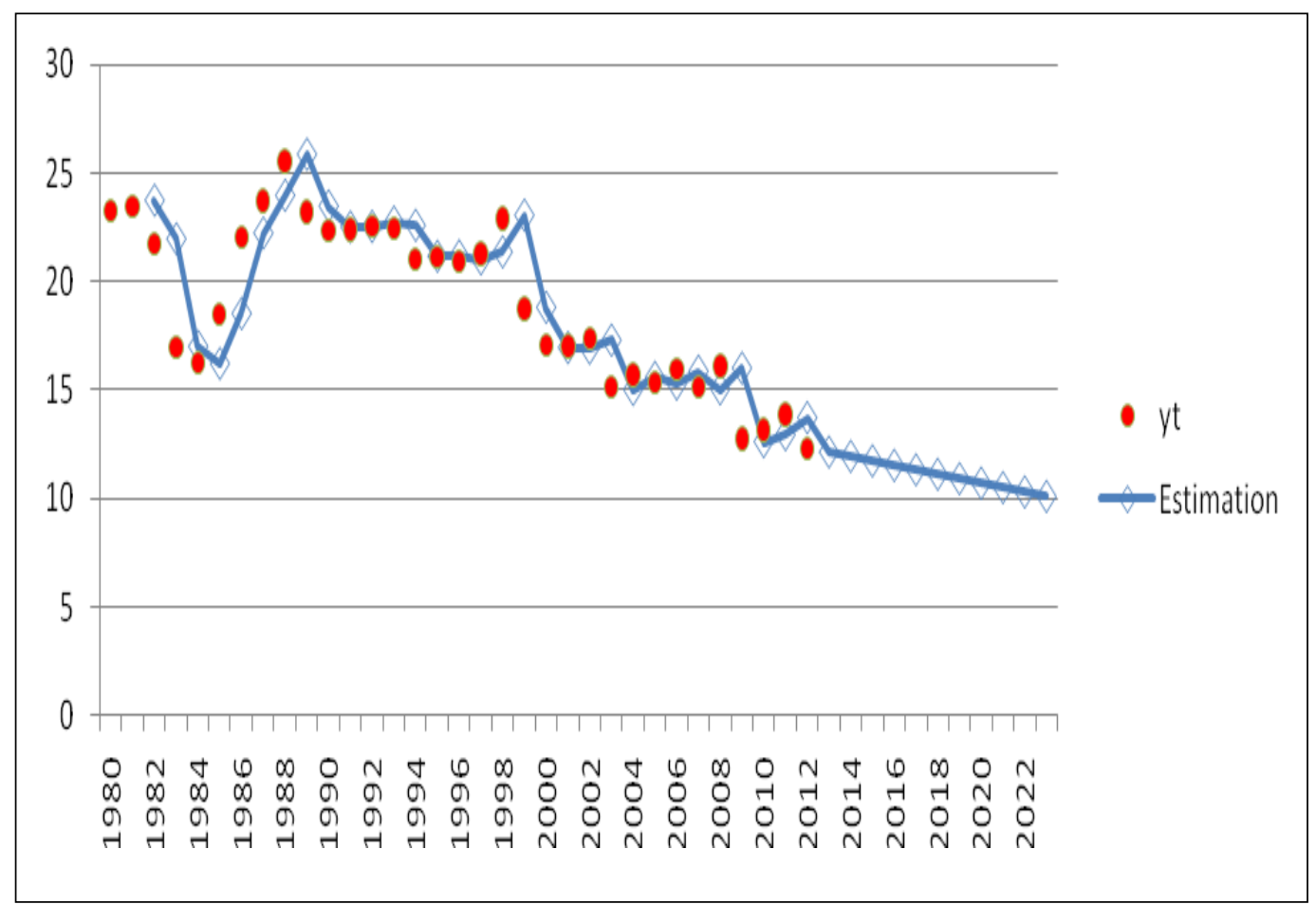

Figure 3: Estimation of “Gross National Savings" Data Using Holt's Linear Exponential Smoothing Method 


\subsubsection{Forecasting results of indicator 4 (Inflation, Average Consumer Prices)}

Table 4: Selection of Method for Forecasting "Inflation, Average Consumer Prices"

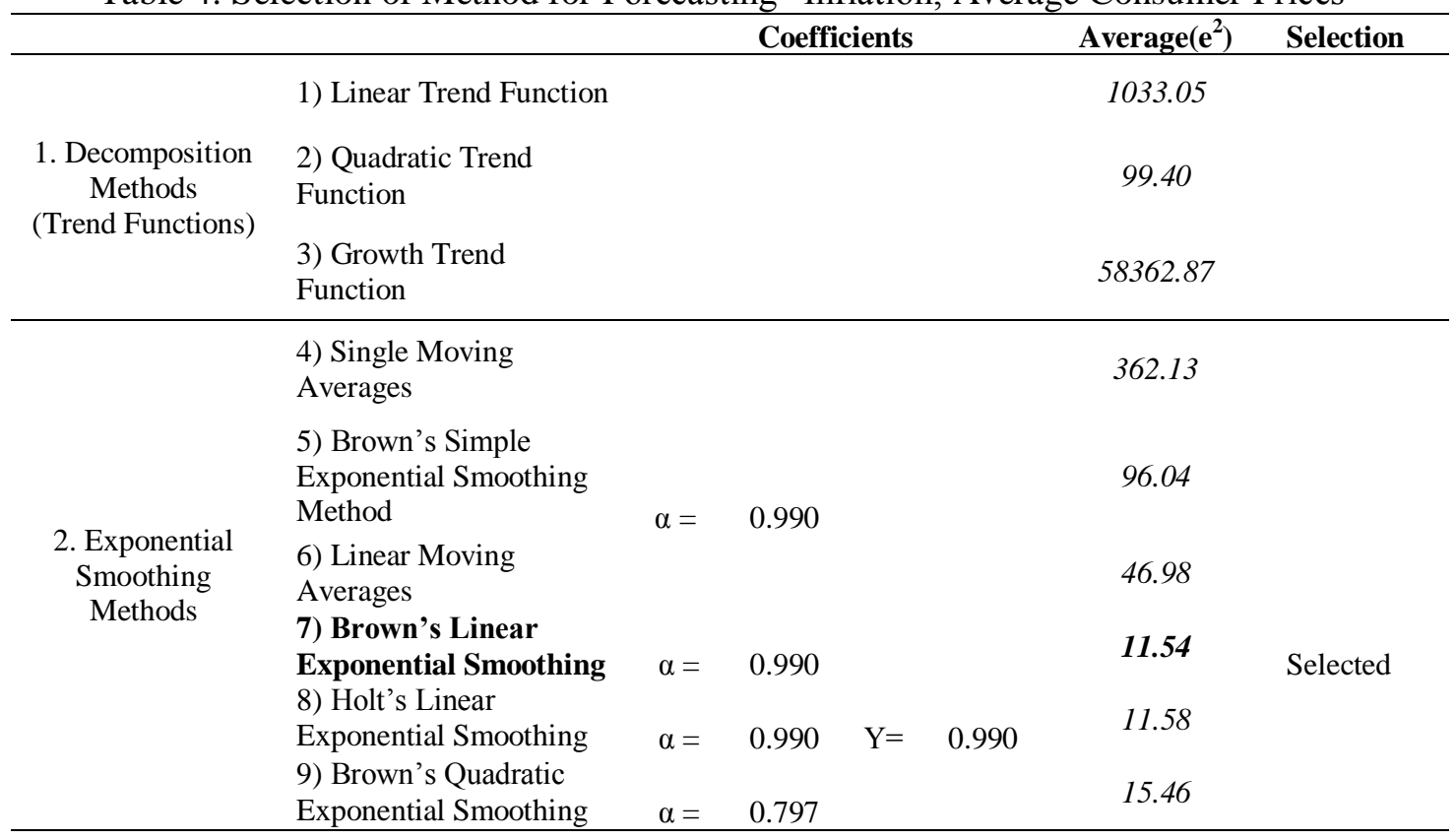

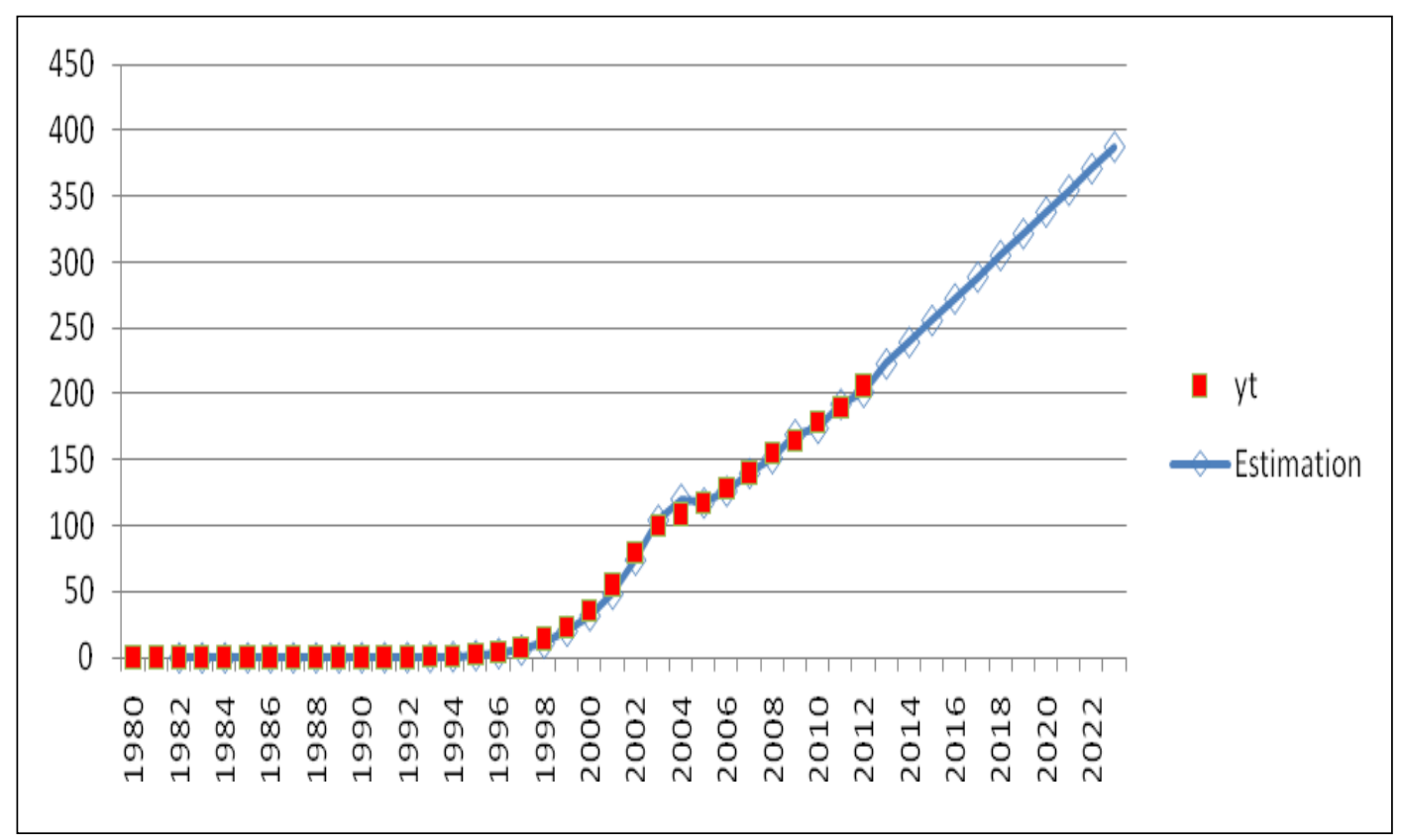

Figure 4: Estimation of “Inflation, Average Consumer Prices” Data Using Brown's Linear Exponential Smoothing Method 


\subsubsection{Forecasting results of indicator 5 (Volume of Imports of Goods and Services)}

Table 5: Selection of Method for Forecasting "Volume of Imports of Goods and Services" Coefficients Average $\left(\mathrm{e}^{2}\right) \quad$ Selection

1.

1) Linear Trend Function

282.56

Decomposition

Methods

2) Quadratic Trend Function

282.52 Selected

(Trend
3) Growth Trend Function

4) Single Moving Averages

350.14

5) Brown's Simple Exponential Smoothing Method

$\alpha \quad 0.010$

328.49

6) Linear Moving Averages

575.77

2. Exponential

7) Brown's Linear Exponential

Smoothing

Smoothing Method

$\alpha \quad 0.015$

286.72

8) Holt's Linear Exponential

Smoothing Method

$\begin{array}{llll}\alpha & 0.821 & \mathrm{Y} & 0.179\end{array}$

$1,028.18$

9) Brown's Quadratic Exponential Smoothing Technique

$\alpha \quad 0.010$

286.69

Trend Function of "Volume of Imports of Goods and Services"
$y=11.7238-0.2737 x-0.0025 x^{2}+e_{t}$

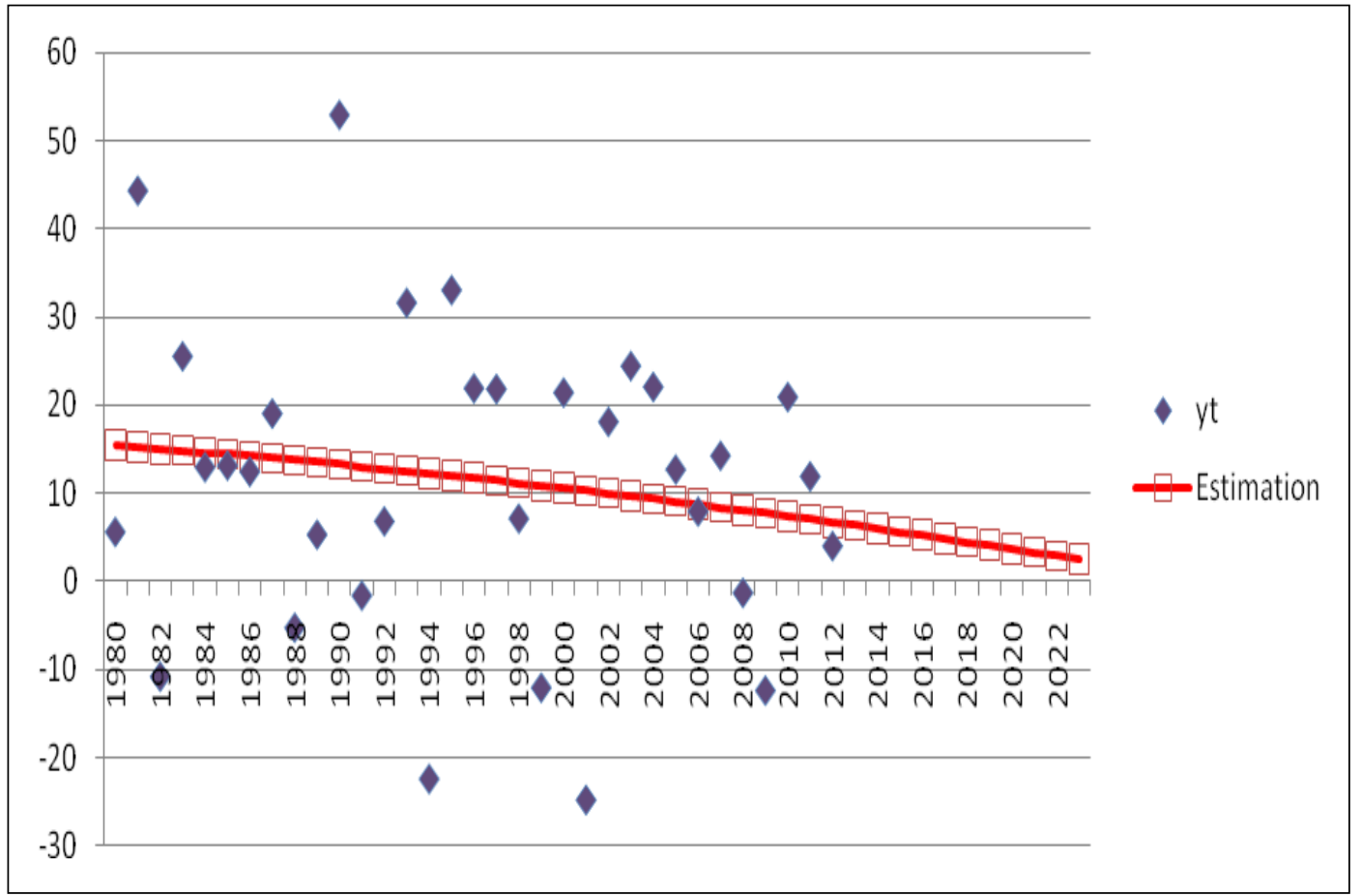

Figure 5: Estimation of "Volume of Imports of Goods and Services" Data Using Decomposition (Quadratic Trend) Method 


\subsubsection{Forecasting results of indicator 6 (Volume of Exports of Goods and Services)}

Table 6: Selection of Method for Forecasting "Volume of Exports of Goods and Services"

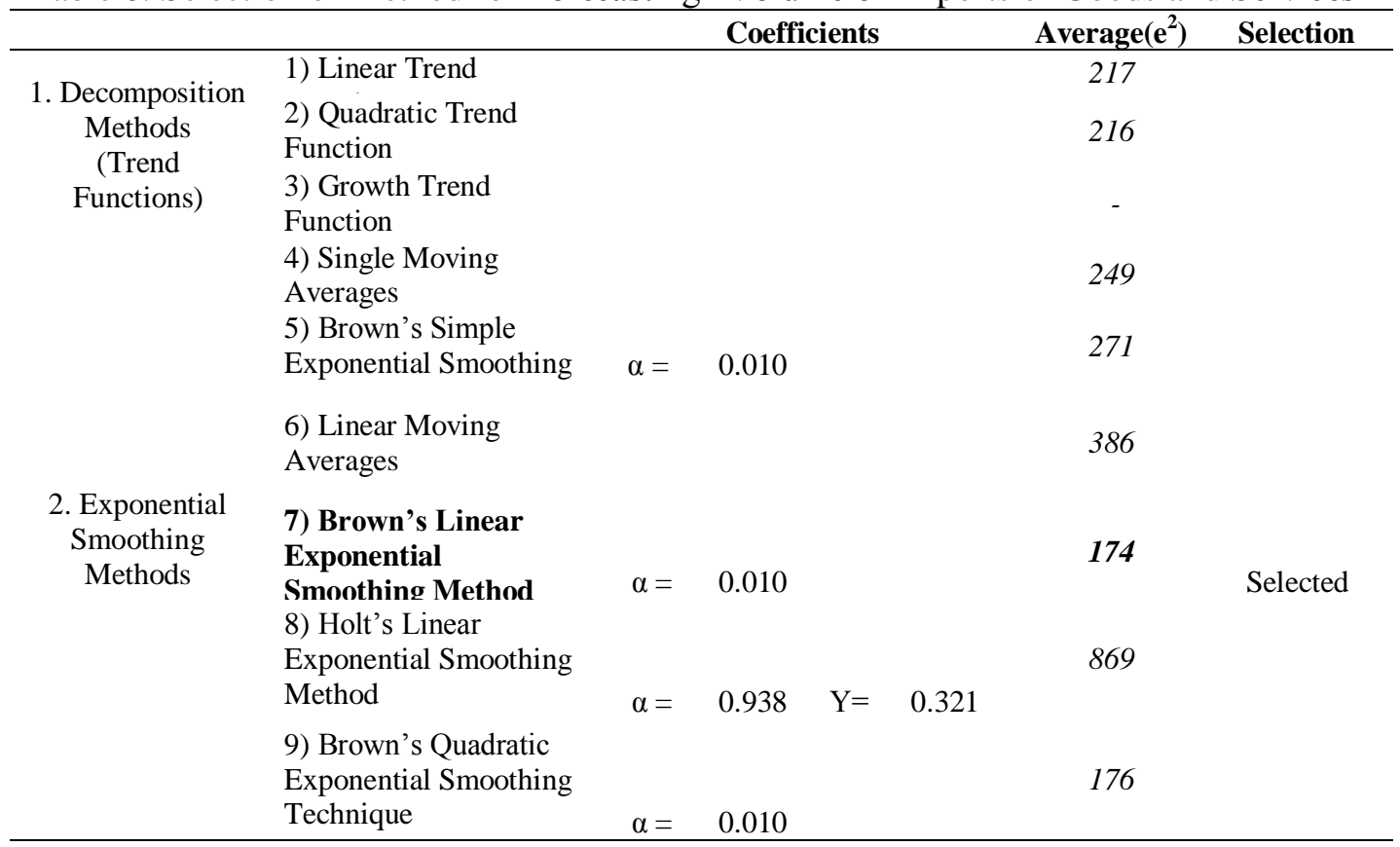

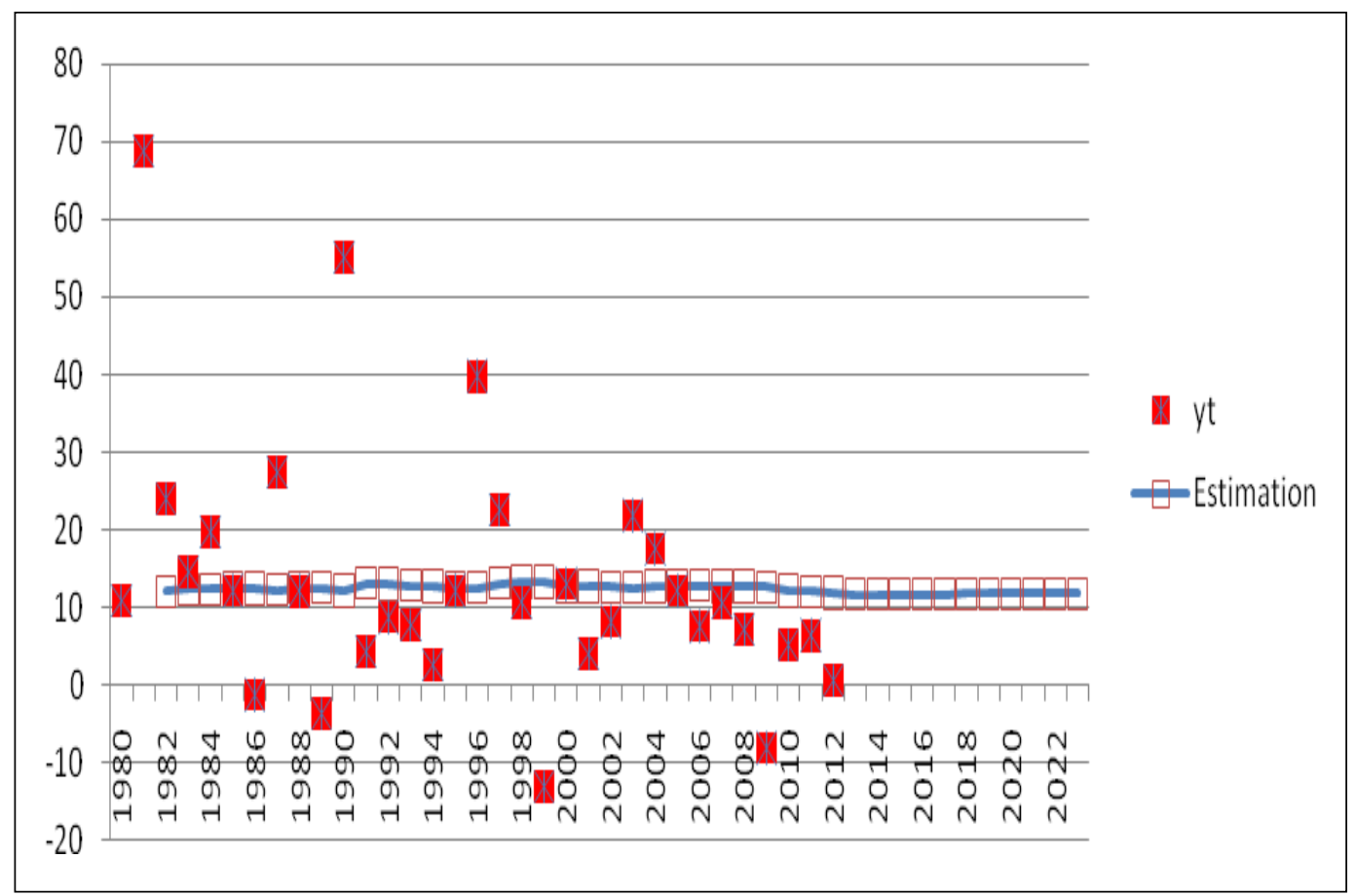

Figure 6: Estimation of "Volume of exports of goods and services" data using Brown's Linear Exponential Smoothing Method 


\subsubsection{Forecasting results of indicator 7 (Unemployment Rate)}

Table 7: Selection of Method for Forecasting "Unemployment Rate"

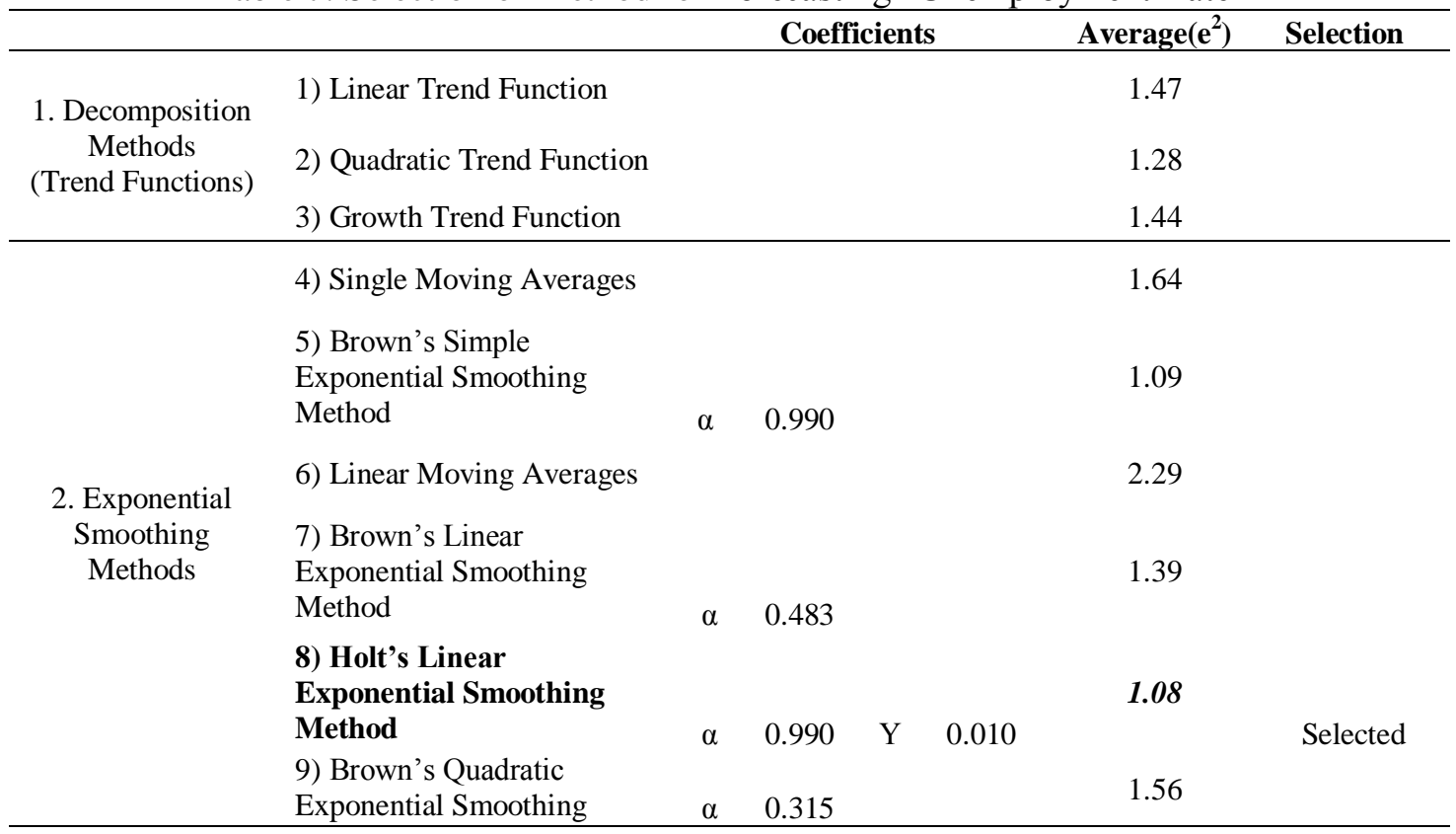

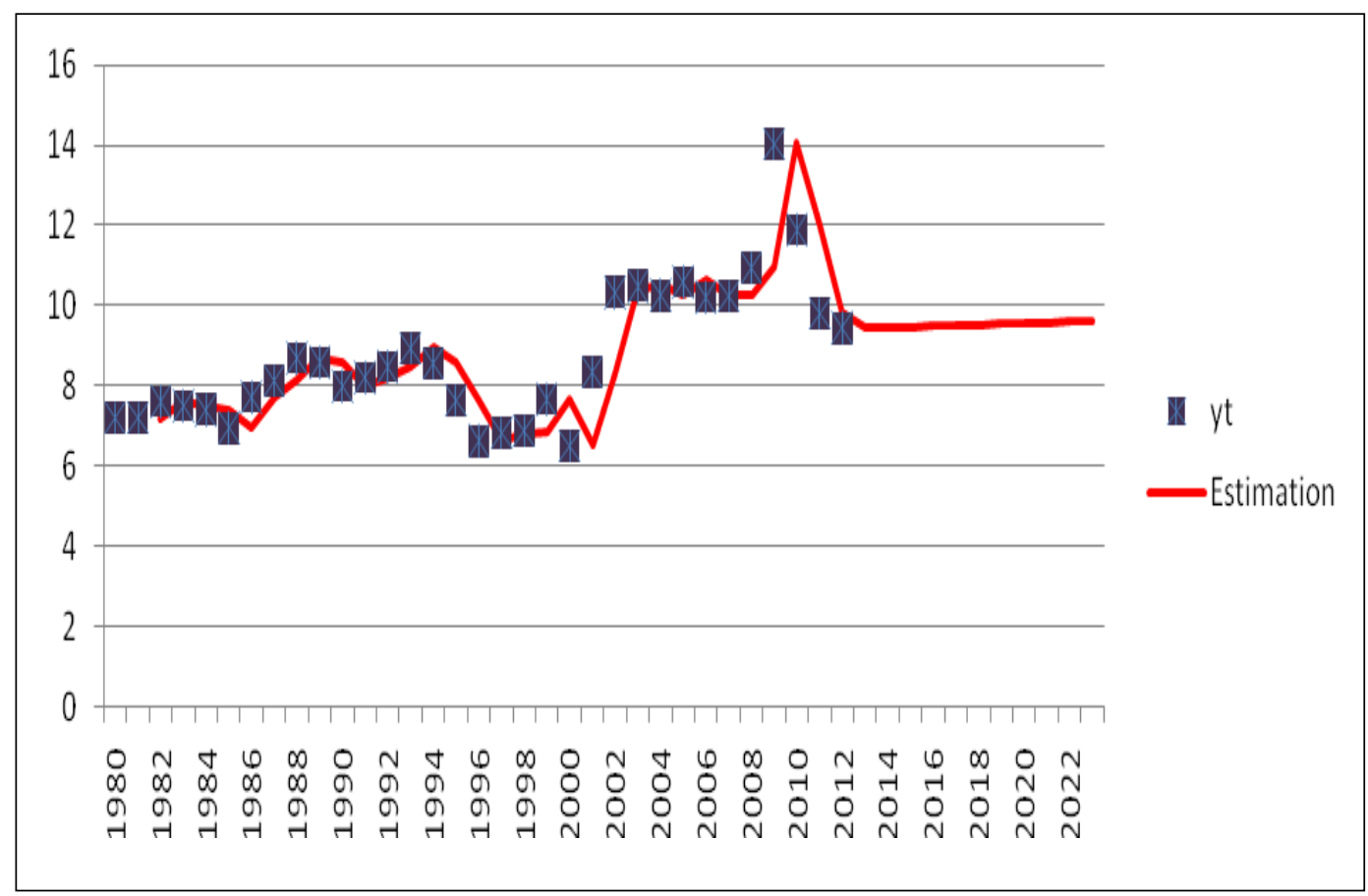

Figure 7: Estimation of "Unemployment Rate” Data Using Holt's Linear Exponential Smoothing Method 


\subsubsection{Forecasting results of indicator 8 (Population)}

Table 8: Selection of Method for Forecasting "Population"

Coefficients

Average $\left(\mathrm{e}^{2}\right) \quad$ Selection

1) Linear Trend Function

0.59

1. Decomposition

Methods

2) Quadratic Trend

Function

0.58

(Trend Functions)

3) Growth Trend

Function

1.26

4) Single Moving

Averages

4.85

5) Brown's Simple

Exponential Smoothing

Method

$\alpha=0.990$

1.42

6) Linear Moving

2. Exponential

Averages

0.57

Smoothing

7) Brown's Linear

Exponential Smoothing Method

$$
\text { (1) }
$$

8) Holt's Linear

Exponential Smoothing

Method

$\alpha=0.696$

9) Brown's Quadratic

Exponential Smoothing

Technique

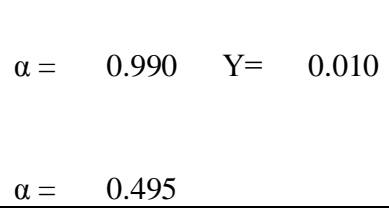

0.37

Selected

0.66

$\alpha=0.495$

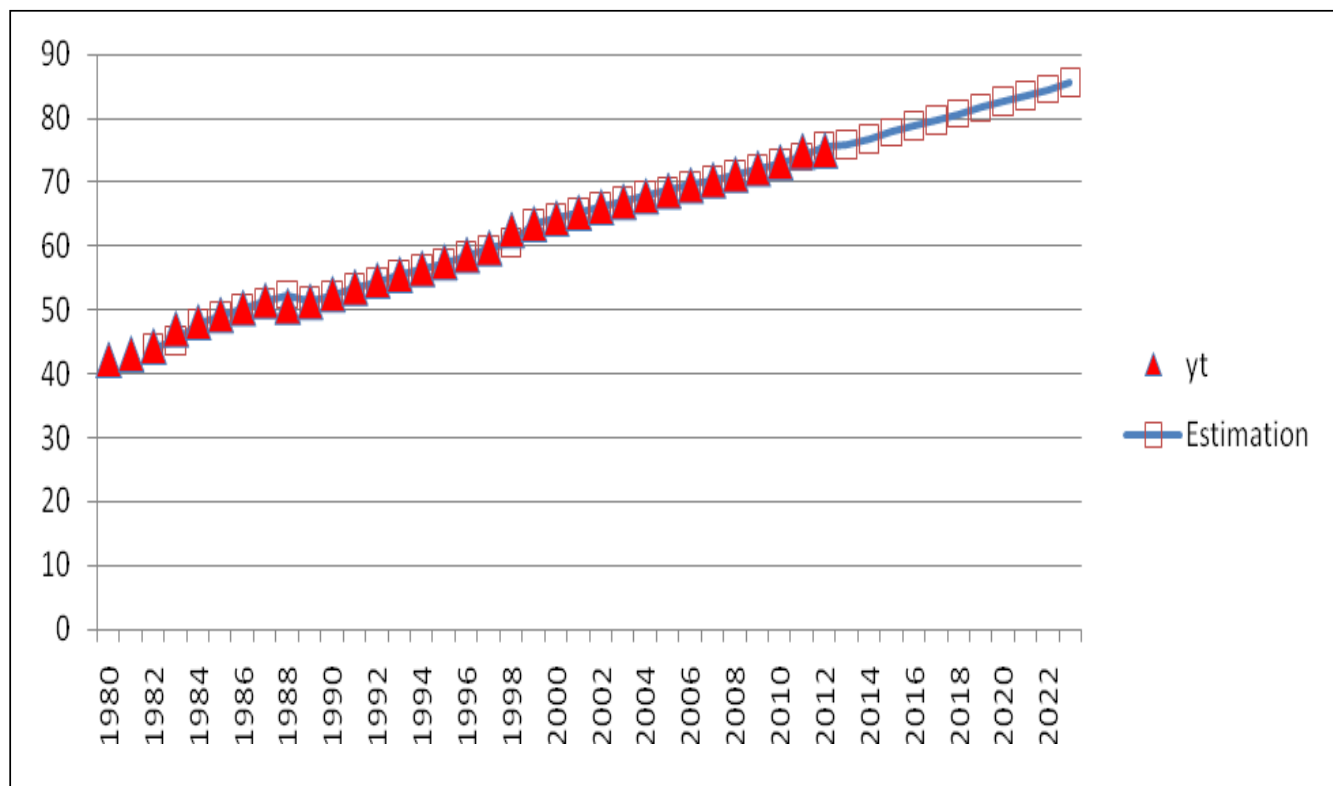

Figure 8: Estimation of "Population” Data Using Holt's Linear Exponential Smoothing Method 
Table 9: Estimated Values of Macro Economic Indicators

\begin{tabular}{|c|c|c|c|c|c|c|c|c|}
\hline & Holt's & Quadratic & Holt's & $\begin{array}{c}\text { Brown' } \\
\mathbf{s}\end{array}$ & $\begin{array}{c}\text { Quadrati } \\
\mathbf{c}\end{array}$ & Brown's & $\begin{array}{c}\text { Holt' } \\
\mathbf{s}\end{array}$ & $\begin{array}{c}\text { Holt' } \\
\mathbf{s}\end{array}$ \\
\hline $\begin{array}{c}\text { Year } \\
\text { s }\end{array}$ & NGPD & $\begin{array}{c}\text { NID_NGP } \\
\text { D }\end{array}$ & $\begin{array}{c}\text { NGSD_NGD } \\
\text { P }\end{array}$ & PCPI & TM_RPC & TX_RPC & LUR & LP \\
\hline 2013 & 817,37 & 19,51542 & 12,12 & 222,99 & 6,34 & 11,72 & 9,44 & 75,87 \\
\hline 2014 & 850,02 & 19,46096 & 11,91 & 239,46 & 5,98 & 11,72 & 9,46 & 76,83 \\
\hline 2015 & 882,68 & 19,41109 & 11,71 & 255,93 & 5,61 & 11,72 & 9,47 & 77,80 \\
\hline 2016 & 915,34 & 19,36579 & 11,50 & 272,40 & 5,24 & 11,72 & 9,49 & 78,77 \\
\hline 2017 & 948,00 & 19,32506 & 11,30 & 288,87 & 4,86 & 11,73 & 9,51 & 79,73 \\
\hline 2018 & 980,65 & 19,28892 & 11,09 & 305,34 & 4,48 & 11,73 & 9,53 & 80,70 \\
\hline 2019 & 1013,3 & 19,25735 & 10,89 & 321,81 & 4,09 & 11,73 & 9,54 & 81,67 \\
\hline 2020 & 1045,9 & 19,23036 & 10,68 & 338,28 & 3,70 & 11,74 & 9,56 & 82,63 \\
\hline 2021 & 1078,6 & 19,20795 & 10,48 & 354,75 & 3,30 & 11,74 & 9,58 & 83,60 \\
\hline 2022 & 1111,2 & 19,19011 & 10,27 & 371,22 & 2,90 & 11,74 & 9,60 & 84,57 \\
\hline 2023 & 1143,9 & 19,17686 & 10,07 & 387,69 & 2,49 & 11,74 & 9,62 & 85,53 \\
\hline
\end{tabular}

\subsection{Results of Artificial Neural Network}

To perform an ANN analysis, we use Alyuda Nero-intelligence 2.2 (Build 577) software. The process of performing a neural network successfully predicting a financial time series has some steps, i.e. data preparation, designing, training, testing and forecasting.

\subsubsection{Data preparation}

In this paper, all the variables are linearly scaled into the interval [-1,1] by using corresponding scaling factor for each variable.

Each variable are treated as a time series and lagged series used for prediction. We used 3 or 4 lagged series, i.e. for 3 lagged series; first, second and third period lags are used to predict the original variable. By this way, each lag of the series become an estimator and represent as an input neuron in ANN.

Common practice is to divide the time series into three distinct sets called the training, testing and validation sets. The training set is the largest set and is used by neural network to learn the patterns present in data. The testing set, ranging in size from $10 \%$ to $30 \%$ of the training set, is used to evaluate the generalization ability of a supposedly trained network. A final check on the validation set chosen must strike a balance between obtaining a sufficient sample size to evaluate a trained network and having enough remaining observations for both training and testing. The validation set should consist of the most recent contiguous observations. In this work the approach in evaluation neural networks used as fallows; training (68\%), validation (16\%), test sets (16\%).

\subsubsection{Design of networks}

For multilayer perceptrons, there are an infinite number of ways to set up a network. The number of input neurons is trivial but the tasks of selection of the number of hidden layers, the number of the neurons in the hidden layers, the number of input neurons as well as the transfer functions are much more difficult. In this paper, some series have 
three input neurons (three lagged series) some of them have four. All series has one hidden layer with different number of neurons. The activation methods and the ANN models are listed below.

Table 10: Design of Networks

\begin{tabular}{lcl}
\hline & Model & Activation Function \\
\hline NGPD (Gross domestic product, current prices) & $3-3-1$ & Linear \\
NID_NGPD (Total investment) & $3-3-1$ & Hyperbolic Tangent \\
NGSD_NGDP (Gross national savings) & $3-3-1$ & Linear \\
PCPI (Inflation, average consumer prices) & $4-4-1$ & Linear \\
TM_RPCH (Volume of imports of goods and & & \\
services) & $4-6-1$ & Hyperbolic Tangent \\
TX_RPCH (Volume of exports of goods and & & \\
services) & $4-6-1$ & Hyperbolic Tangent \\
LUR (Unemployment rate) & $4-4-1$ & Hyperbolic Tangent \\
LP (Population) & $4-4-1$ & Logistic \\
\hline
\end{tabular}

\subsubsection{Training of networks}

Training a neural network to learn patterns in the data involves iteratively presenting it with examples to the correct known answers. The objective of training is to find the set of weights between the neurons that determine the global minimum of the error function. In this paper, all the networks are trained by using Levenberg-Marquardt training algorithm which uses Levenberg-Marquardt Optimization method. The Levenberg-Marquardt (LM) algorithm is an iterative technique that locates the minimum of a multivariate function that is expressed as the sum of squares of non-linear real-valued functions. It has become a standard technique for non-linear least-squares problems, widely adopted in a broad spectrum of disciplines. LM can be thought of as a combination of steepest descent and the Gauss-Newton method. When the current solution is far from the correct one, the algorithm behaves like a steepest descent method: slow, but guaranteed to converge. When the current solution is close to the correct solution, it becomes a Gauss-Newton method. Next, a short description of the LM algorithm based on the material in is supplied [15].

The termination criteria were set to iteration number of 500 and by error improvement. In all the networks' training phases, training stop reasons were no error improvement. Number of iterations, iteration speeds and error improvements with absolute error of the networks for both training and validation phases are shown below. 
Table 11: Residual and Iteration Statistics

\begin{tabular}{|c|c|c|c|c|c|}
\hline & \multicolumn{2}{|c|}{ Absolute Error } & \multirow{2}{*}{$\begin{array}{c}\text { Error } \\
\text { Improvement }\end{array}$} & \multirow[b]{2}{*}{ Iteration } & \multirow{2}{*}{$\begin{array}{c}\text { Iteration Speed } \\
(\text { ite/sec) }\end{array}$} \\
\hline & Training & Validation & & & \\
\hline$N G P D$ & 147,099 & 147,567 & $1,7310^{-18}$ & 7 & 35 \\
\hline$N I D \_N G P D$ & 2,401 & 1,432 & $6,9310^{-3}$ & 12 & 60 \\
\hline$N G S D \_N G D P$ & 3,542 & 3,250 & $1,7310^{-4}$ & 7 & 35 \\
\hline$P C P I$ & 2,306 & 2,037 & 0 & 501 & 835 \\
\hline$T M \_R P C H$ & 15,046 & 13,676 & $1,3910^{-17}$ & 13 & 32,5 \\
\hline$T X \_R P C H$ & 16,792 & 13,871 & $1,310^{-4}$ & 9 & 45 \\
\hline LUR & 2,007 & 1,518 & $5,0510^{-4}$ & 7 & 17,5 \\
\hline$L P$ & 0,044 & 0,540 & $1,3810^{-8}$ & 372 & 930 \\
\hline
\end{tabular}

\subsubsection{Test of networks}

Mean absolute error of test data, correlation and R-Square as follows:

Table 12: Test Statistics

\begin{tabular}{|c|c|c|c|c|}
\hline & \multicolumn{2}{|c|}{ Absolute Error } & \multirow[b]{2}{*}{ Correlation } & \multirow[b]{2}{*}{ R-Square } \\
\hline & Mean & Std. Dev. & & \\
\hline$N G P D$ & 44,991 & 44,399 & 0,963 & 0,928 \\
\hline$N I D \_N G P D$ & 1,712 & 1,750 & 0,552 & 0,305 \\
\hline$N G S D \_N G D P$ & 1,176 & 0,889 & 0,925 & 0,856 \\
\hline$P C P I$ & 2,790 & 2,509 & 0,999 & 0,997 \\
\hline$T M \_R P C H$ & 10,491 & 7,504 & 0,643 & 0,413 \\
\hline$T X \_R P C H$ & 7,653 & 5,389 & 0,723 & 0,522 \\
\hline LUR & 0,656 & 0,567 & 0,873 & 0,762 \\
\hline$L P$ & 0,386 & 0,368 & 0,998 & 0,996 \\
\hline
\end{tabular}

The fitness graphics of target and output of networks are shown as follows:

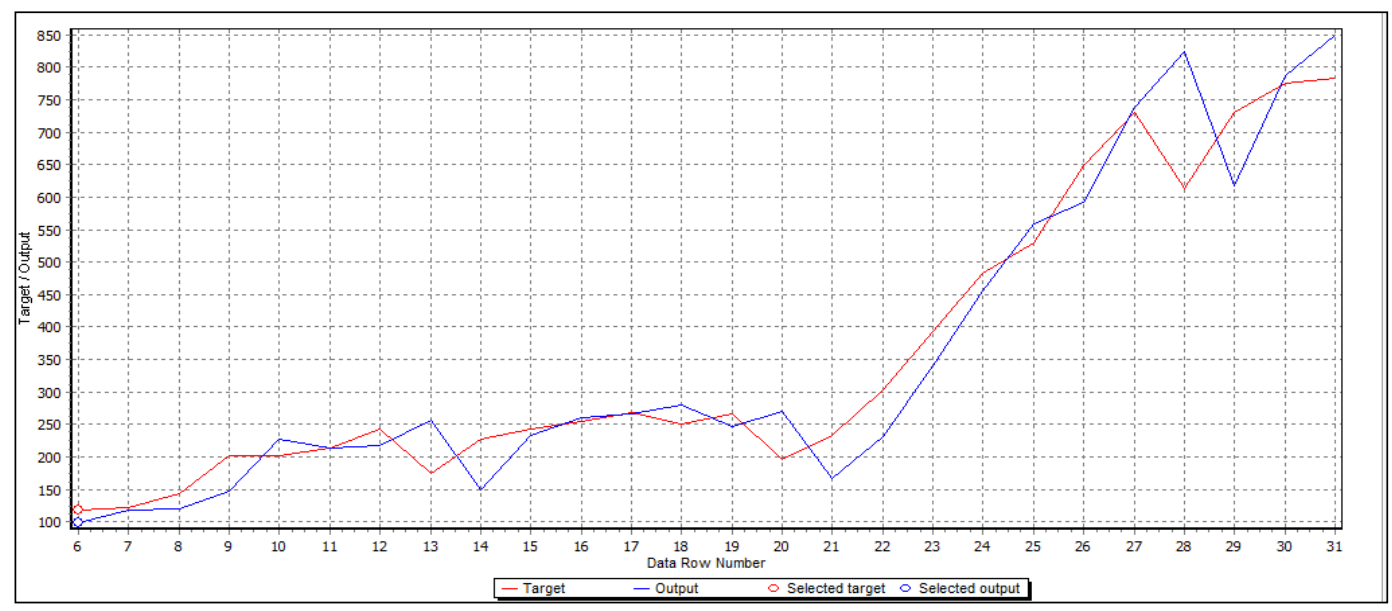

Figure 9: Fitness of Actual "Gross Domestic Product, Current Prices, NGPD” vs. Output 


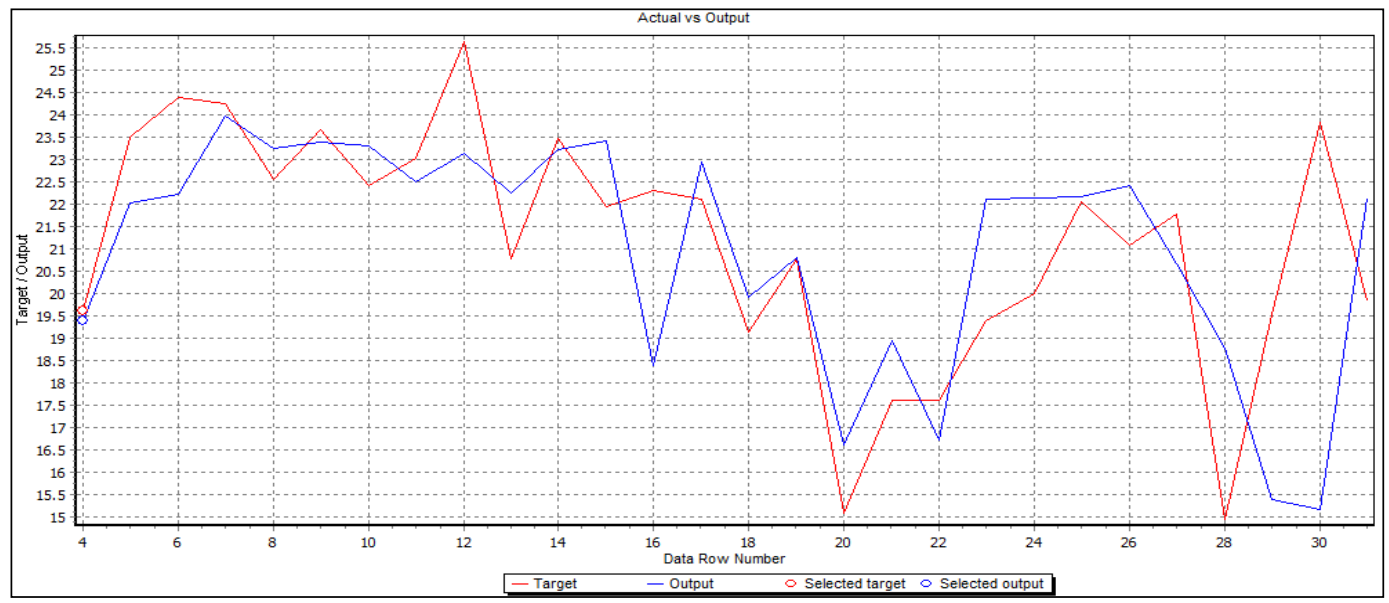

Figure 10: Fitness of Actual “Total Investment, NID_NGPD” vs. Output

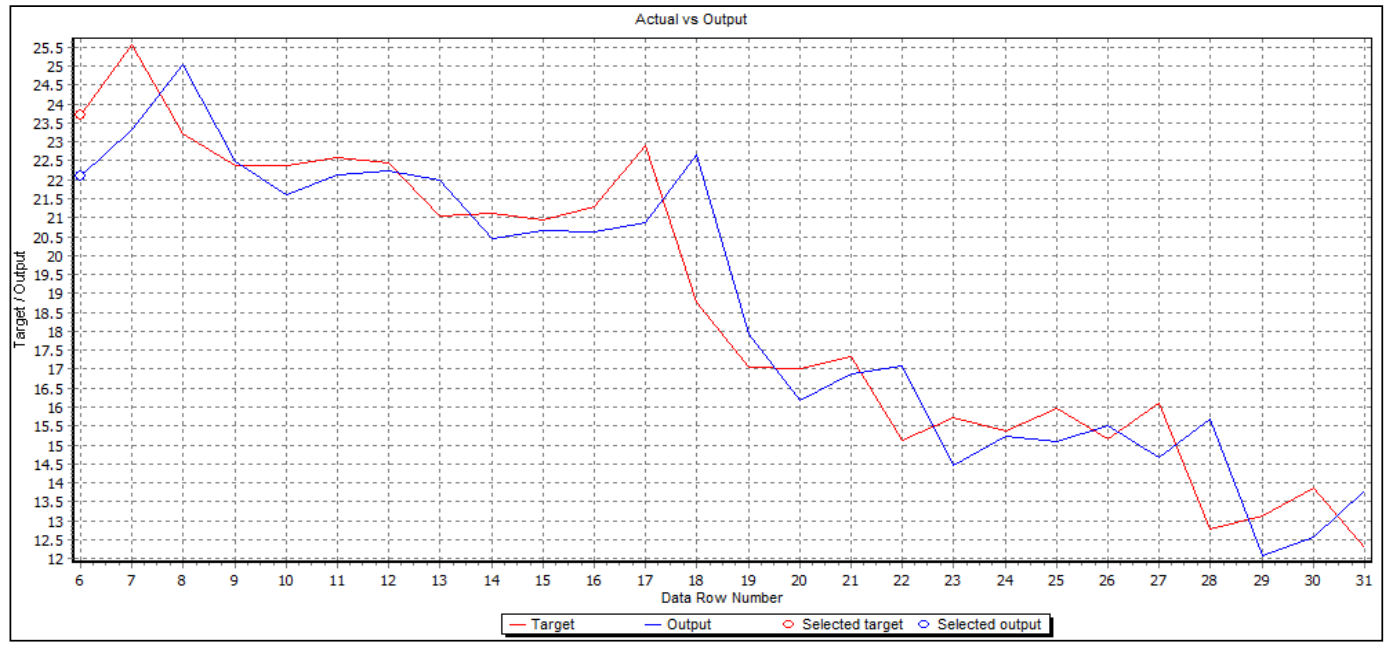

Figure 11: Fitness of Actual “Gross National Savings, NGSD_NGDP” vs. Output

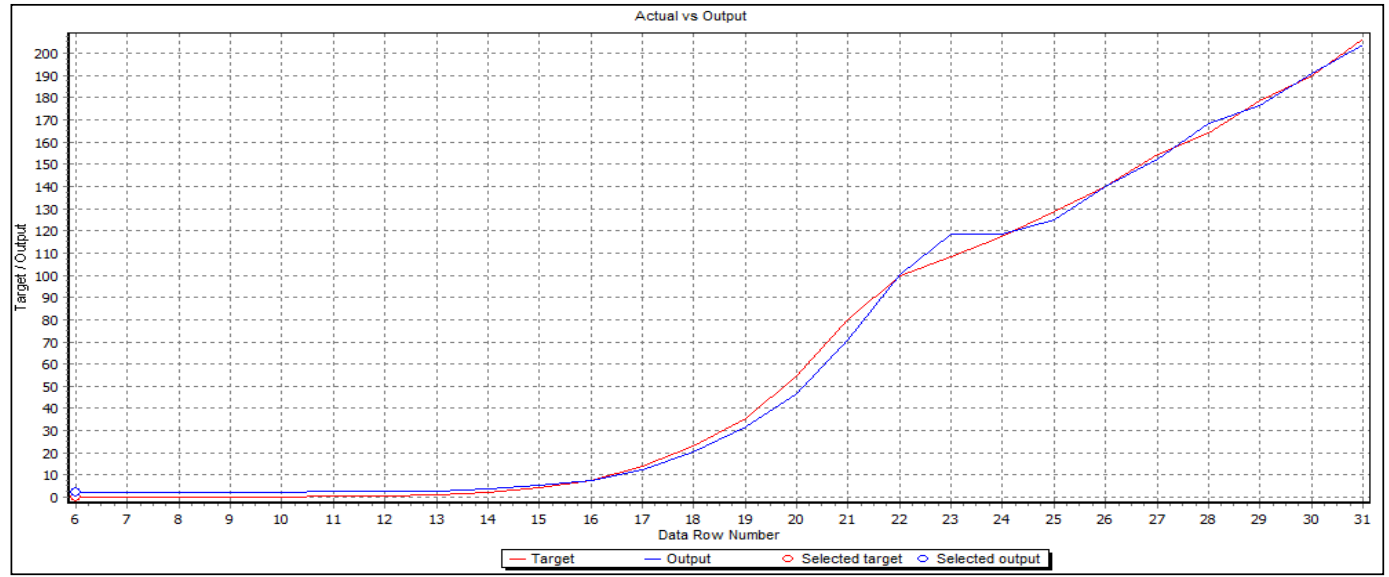

Figure 12: Fitness of Actual "Inflation, Average Consumer Prices, PCPI" vs. Output 


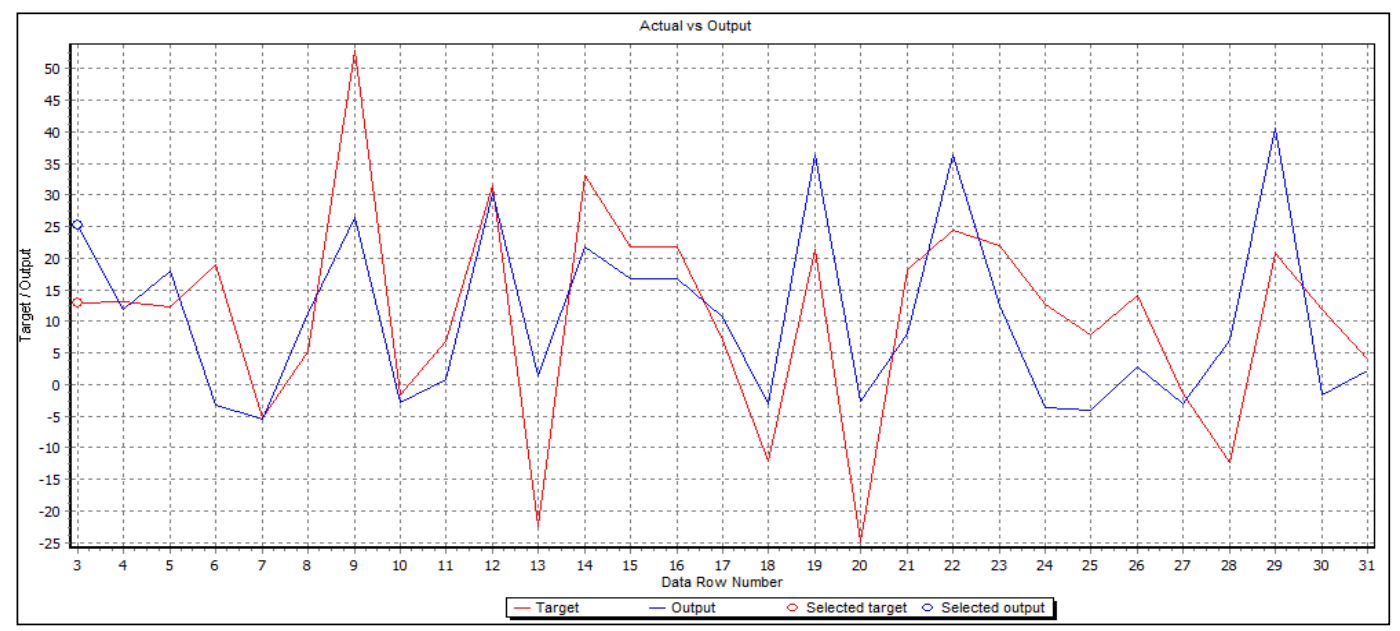

Figure 13: Fitness of Actual "Volume of Imports of Goods and Services, TM_RPCH" vs. Output

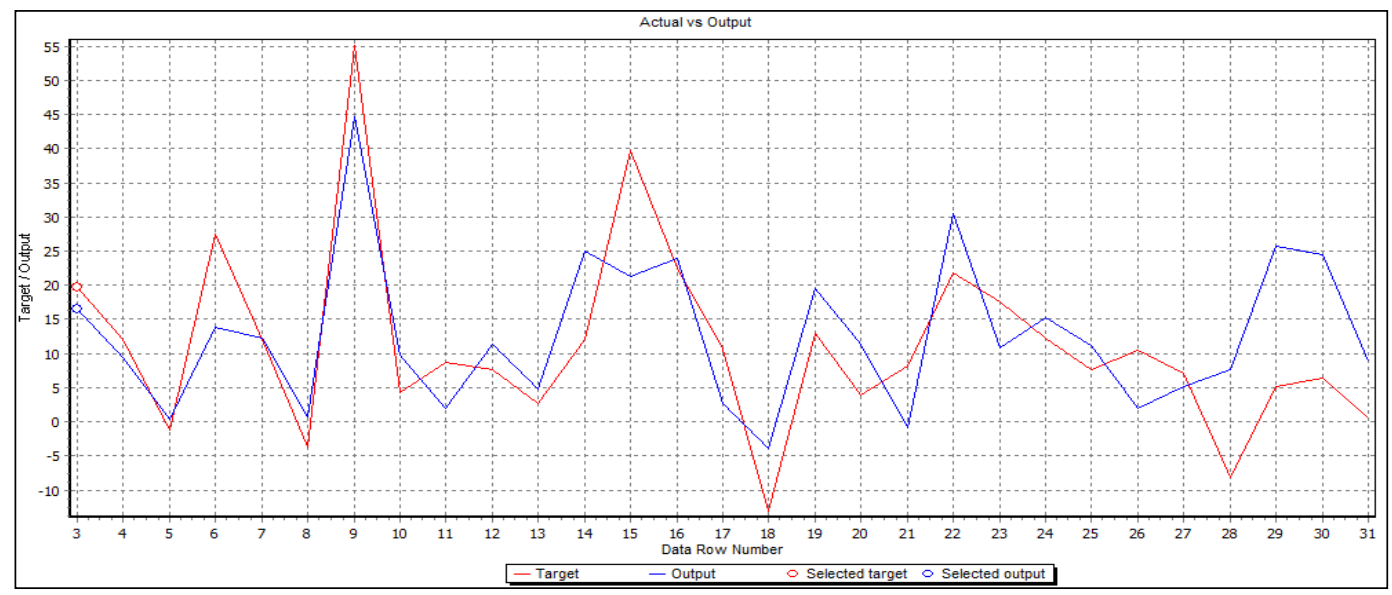

Figure 14: Fitness of Actual "Volume of Exports of Goods and Services, TX_RPCH" vs. Output

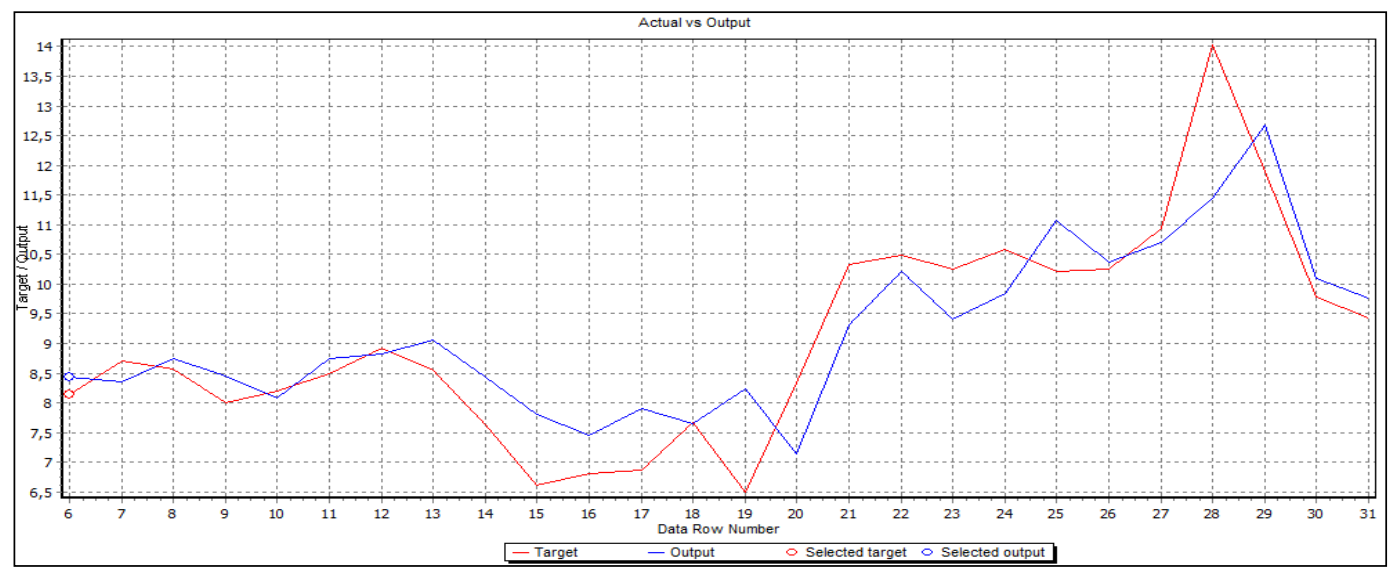

Figure 15: Fitness of Actual "Unemployment Rate, LUR” vs. Output 


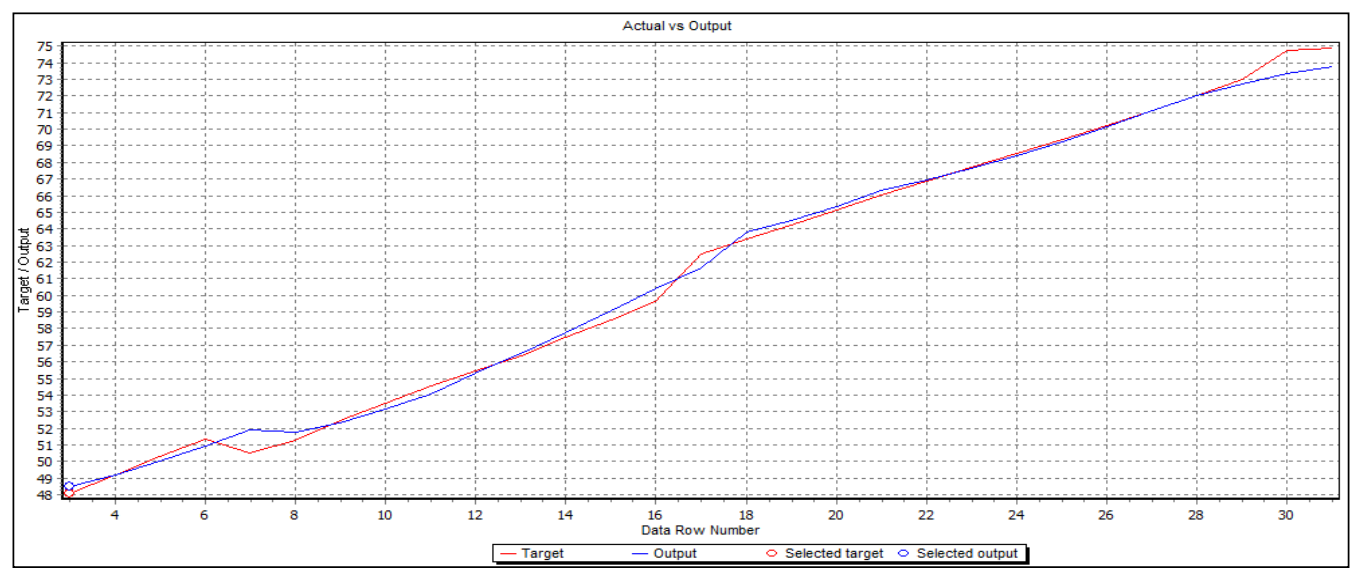

Figure 16: Fitness of Actual "Population, LP" vs. Output

\subsubsection{Forecasting}

After the learning session, for all of the variables, series of estimations from end of the year 2013 to 2023 were performed as follows:

Table 13: Estimation of Variables

\begin{tabular}{|c|c|c|c|c|c|c|c|c|}
\hline Yea & NGP & NID_NGP & NGSD_NG & PCP & TM_RPC & TX_RPC & LU & LP \\
\hline 201 & 820,0 & 20,96 & 11,85 & 211, & 28,772 & 34,389 & 10,4 & 76,3 \\
\hline 201 & 874,0 & 21,72 & 11,36 & 220, & $-8,715$ & 30,030 & 11,5 & 78,0 \\
\hline 201 & 946,9 & 22,05 & 10,84 & 231, & 5,117 & 5,279 & 12,4 & 79,9 \\
\hline 201 & 1.037, & 17,55 & 10,37 & 245, & 37,094 & 7,512 & 12,7 & 81,9 \\
\hline 201 & 1.147, & 17,89 & 9,90 & 260, & 2,687 & 0,299 & 13,0 & 84,0 \\
\hline 201 & 1.275, & 15,27 & 9,43 & 276, & $-0,052$ & $-0,075$ & 13,4 & 86,1 \\
\hline 201 & 1.426, & 21,31 & 8,96 & 294, & 37,077 & 27,879 & 13,5 & 88,4 \\
\hline 202 & 1.600, & 22,14 & 8,49 & 312, & $-5,192$ & 26,972 & 13,6 & 90,7 \\
\hline 202 & 1.802, & 22,15 & 8,02 & 331, & 2,636 & 17,349 & 13,6 & 93,2 \\
\hline 202 & 2.034, & 17,79 & 7,55 & 350, & 37,426 & 0,443 & 13,6 & 95,7 \\
\hline 202 & 2.302, & 20,04 & 7,08 & 371, & 0,762 & 5,188 & 13,7 & 98,4 \\
\hline
\end{tabular}

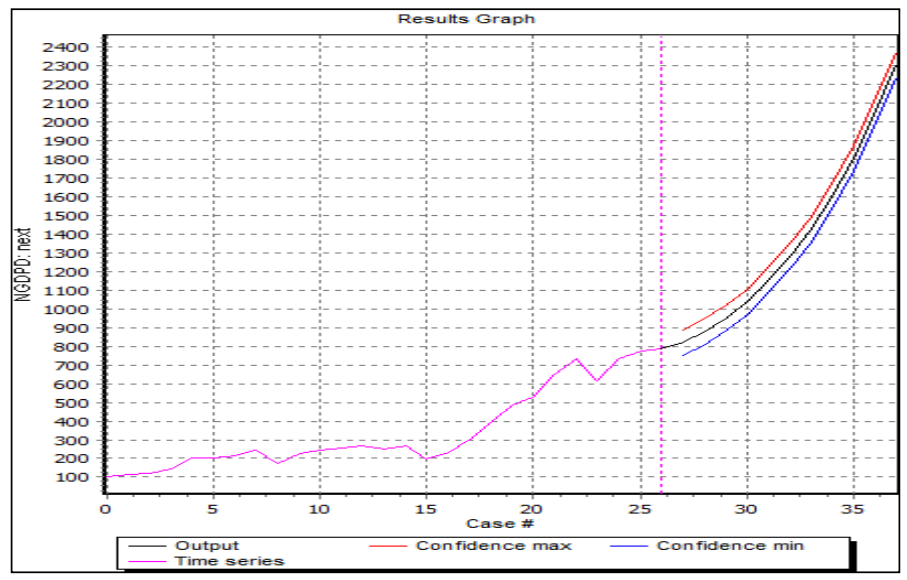

Figure 17: Estimation of "Gross Domestic Product, Current Prices, NGPD” 


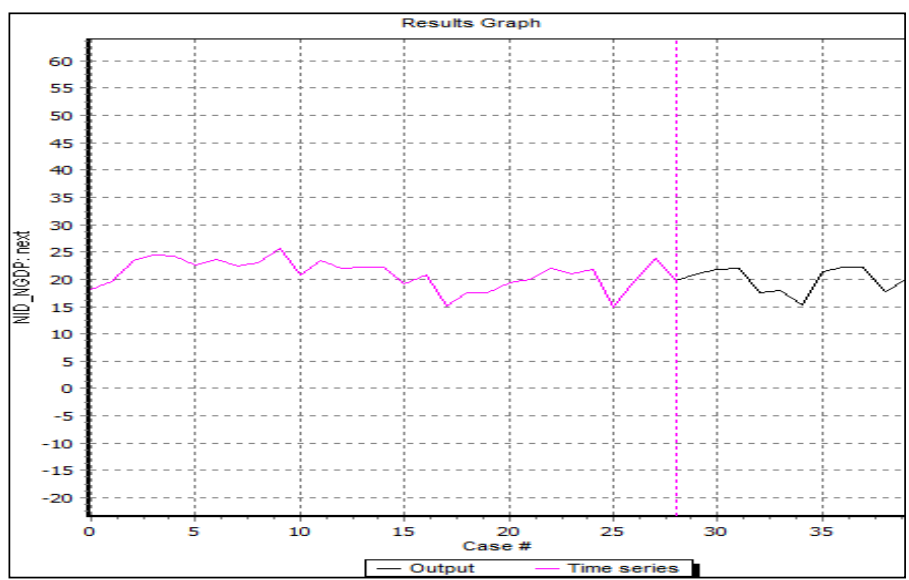

Figure 18: Estimation of "Total Investment, NID_NGPD"

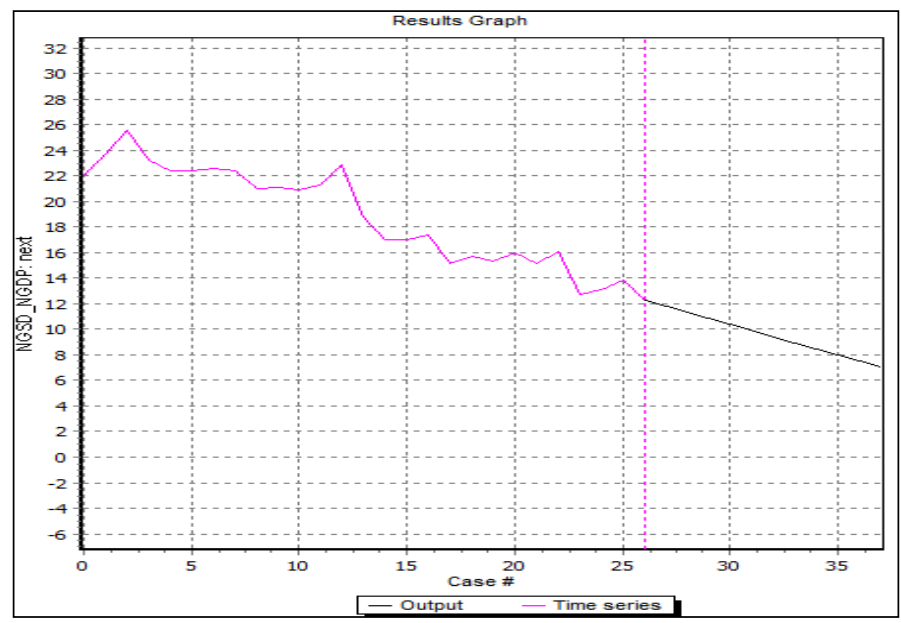

Figure 19: Estimation of "Gross National Savings, NGSD_NGDP"

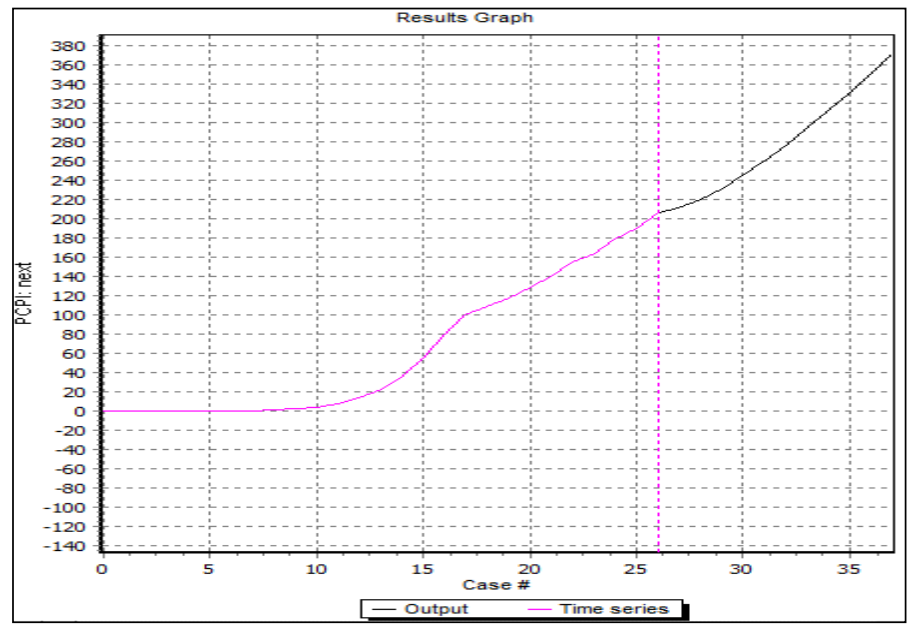

Figure 20: Estimation of "Inflation, Average Consumer Prices, PCPI" 


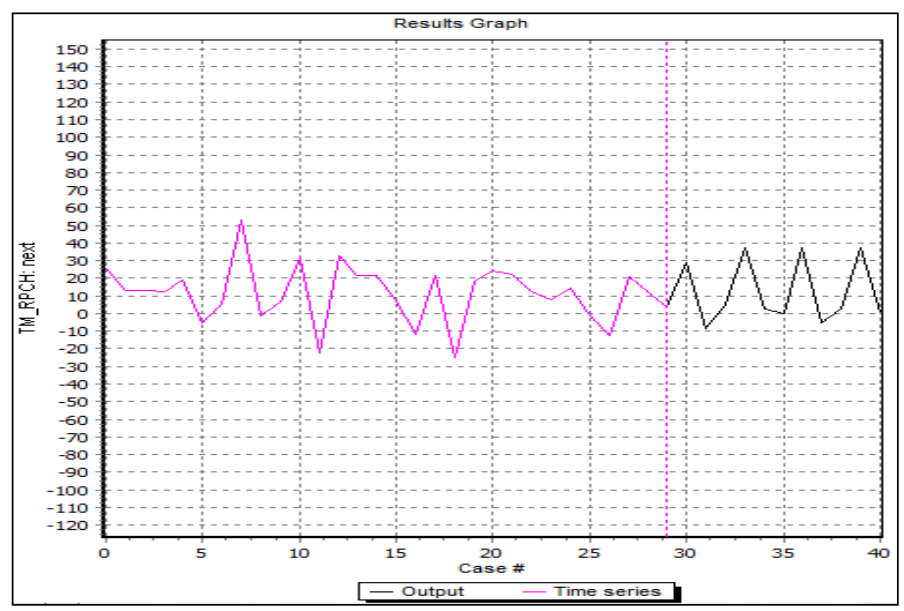

Figure 21: Estimation of "Volume of Imports of Goods and Services, TM_RPCH"

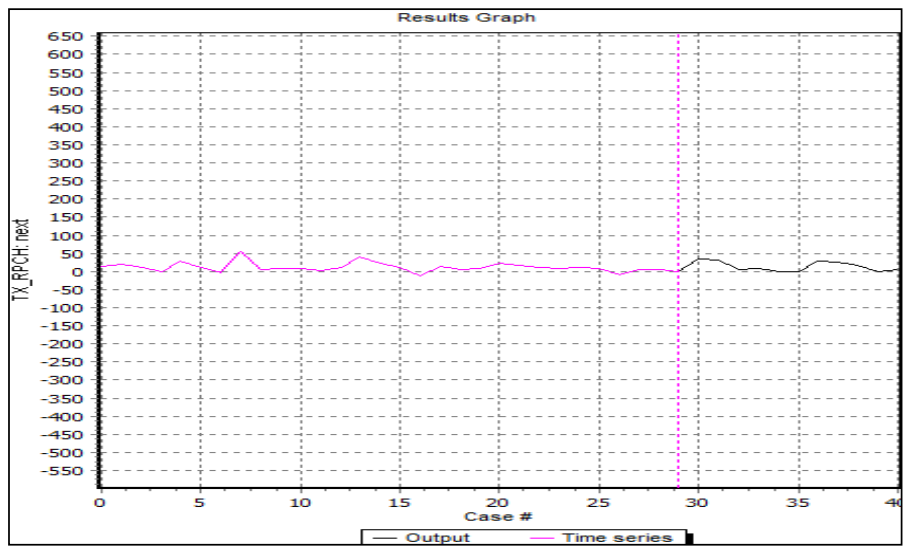

Figure 22: Estimation of "Volume of Exports of Goods and Services, TX_RPCH"

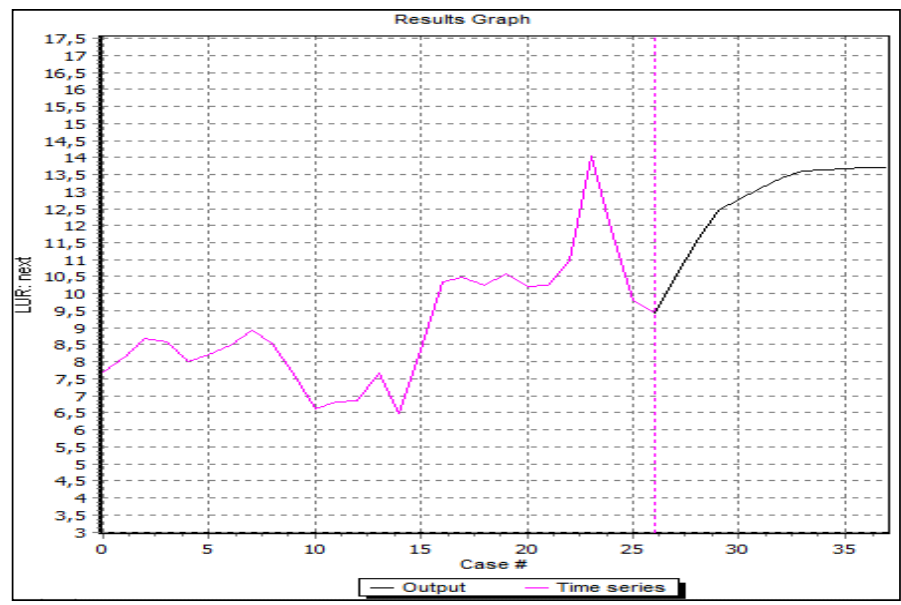

Figure 23: Estimation of "Unemployment Rate, LUR" 


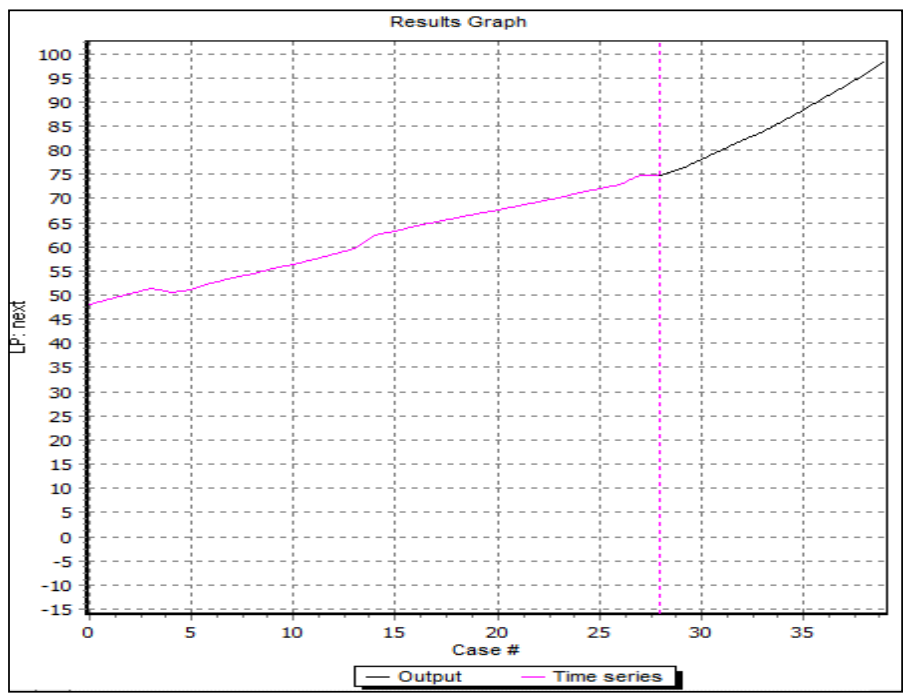

Figure 24: Estimation of "Population, LP"

\subsection{Comparison of Traditional Time Series Methods' and Artificial Neural Networks' Results}

Smoothing methods have good short-term accuracy. Also their simplicity is one of the other advantages. Large amount of historical data are not required. However in smoothing methods choosing smoothing coefficient ( $\alpha$ and/or $\gamma$ ) properly is very important. It affects the quality of forecasting.

Neural networks are universal functions approximation and they can model any continuous and nonlinear function to and desired accuracy, and do not have any assumption about input or residual probability distribution as regression analyze. Theoretically, there can be an infinite number of ways to set up a network. The tasks of selection of the number of hidden layers, the number of the neurons in the hidden layers, the number of input neurons as well as the transfer functions are effect the outcome of networks. Parameters are influential on performance of network. Choosing parameters of ANN is depends on some criteria, i.e. number of input and target variables, complexity and structure of data, theoretical knowledge and facts about study area and previous experiences on ANN. Number of cases and initial values of weights are other important criteria that effect the performance of networks. In this paper, the numbers of cases are less to set up an accurate network. Every combination of parameters gave distinct type of approximations. Hence, choosing the right network was so confusing and needed some theoretical knowledge on macro economy.

In forecasting phase, there were slightly differences between classic time series analysis and neural networks. These differences shown on the graphics below: 


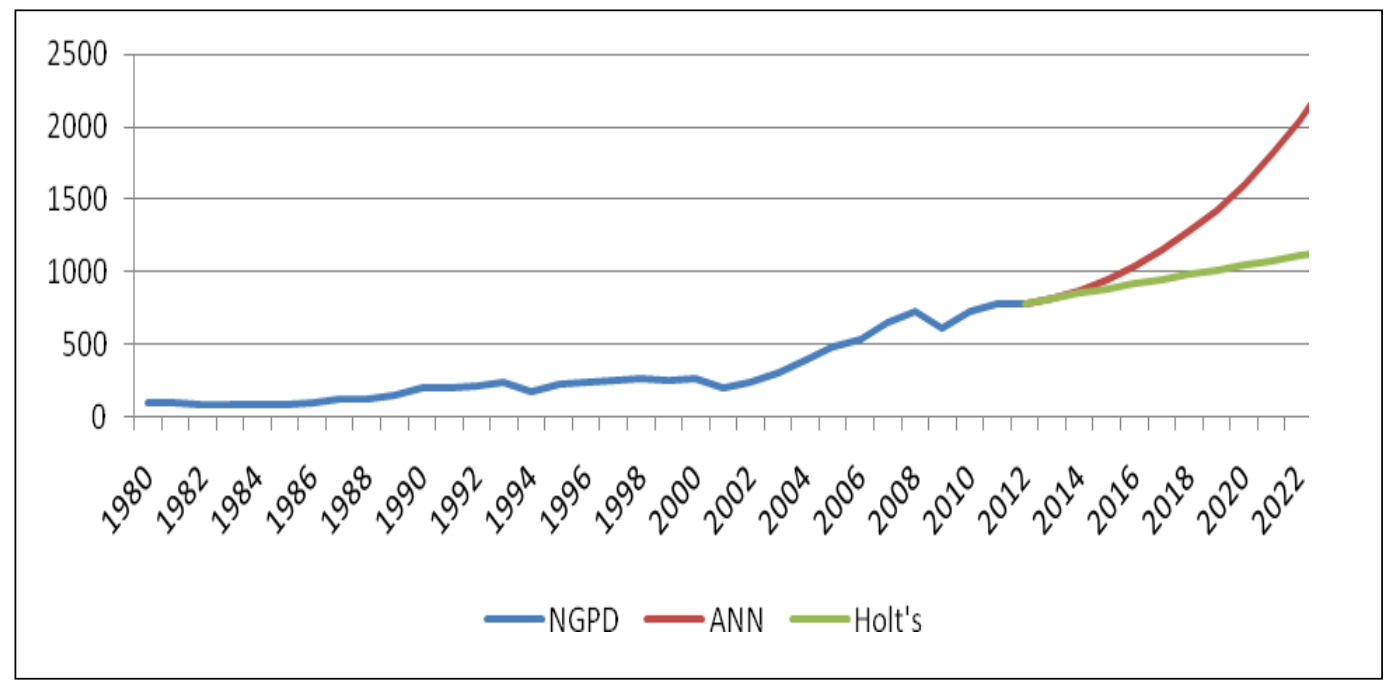

Figure 25: Comparison of “Gross Domestic Product (Volume, NGDPD)” Estimations

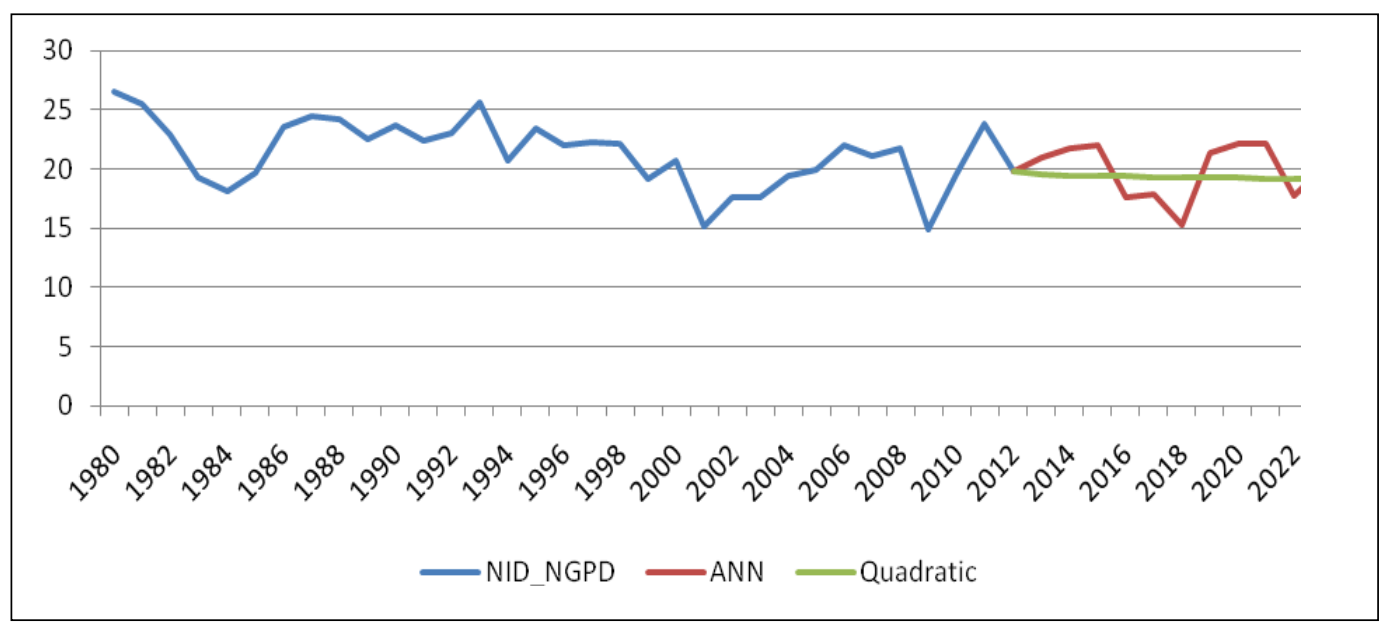

Figure 26: Comparison of "Total Investment (NID_NGDP)" Estimations

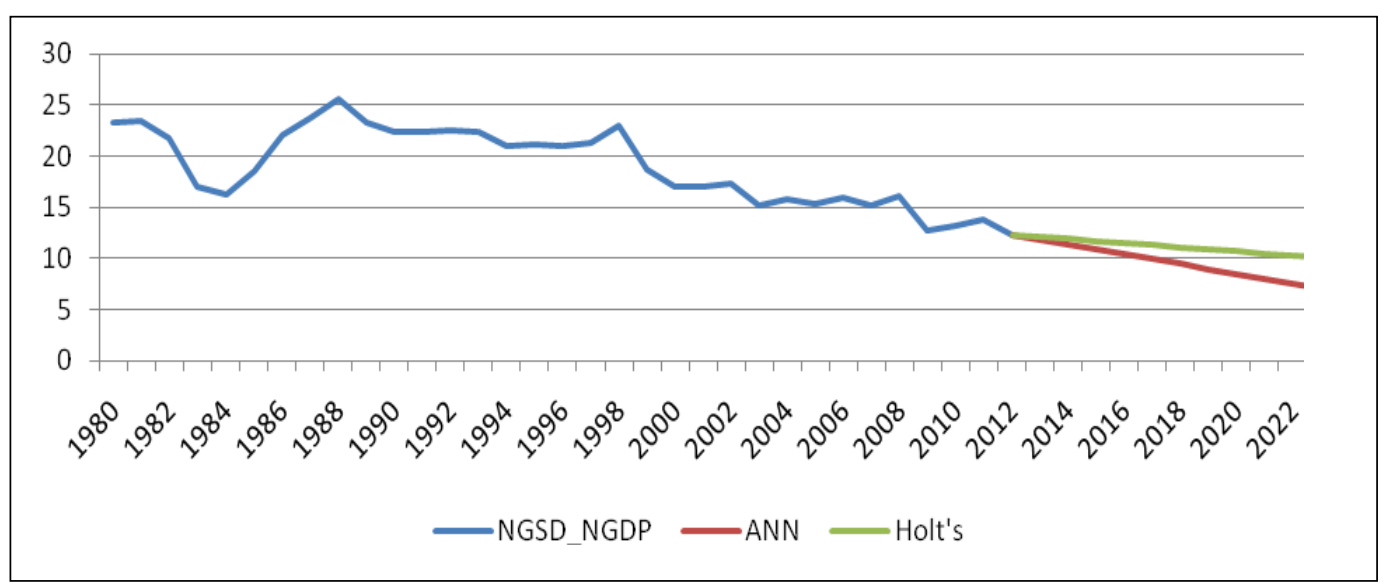

Figure 27: Comparison of "Gross National Savings (NGSD_NGDP)" Estimations 


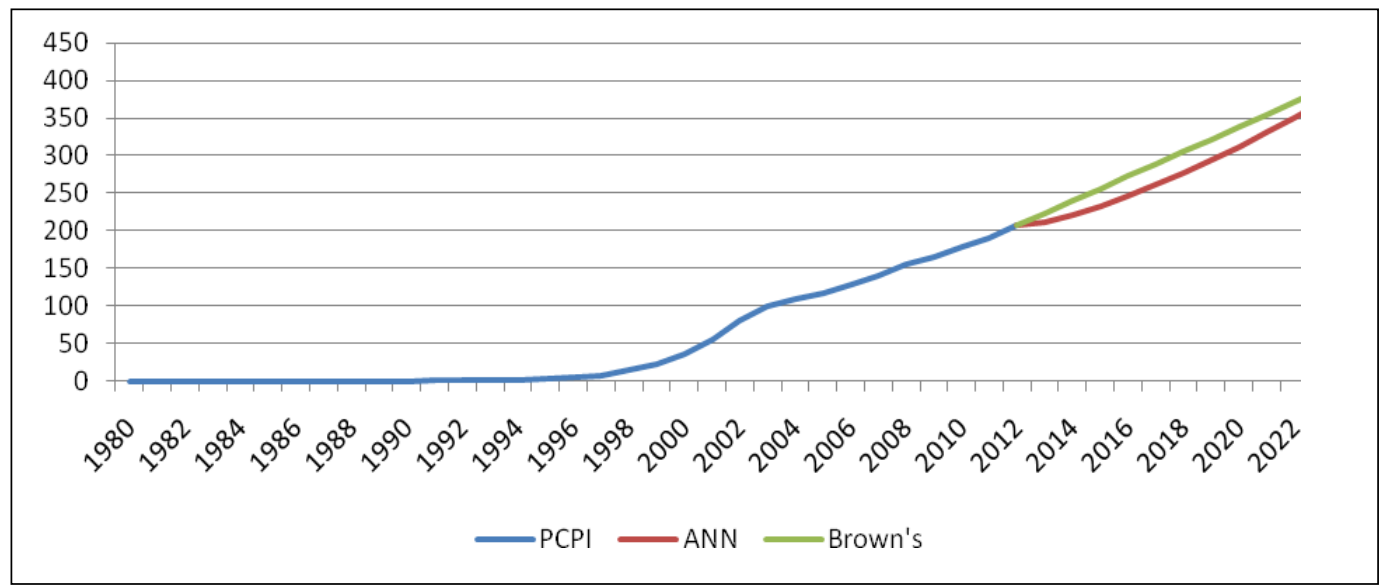

Figure 28: Comparison of "Inflation (Average Consumer Prices, PCPI)" Estimations

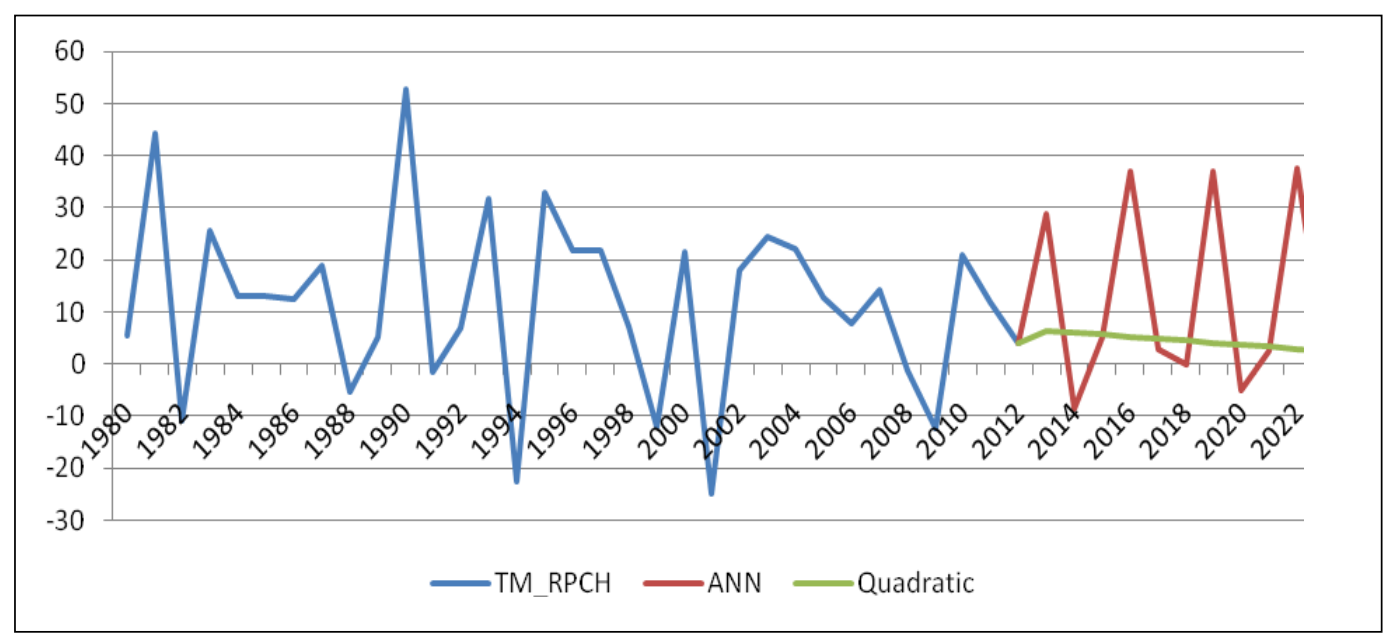

Figure 29: Comparison of "Volume of Exports of Goods and Services (TX_RPCH)" Estimations

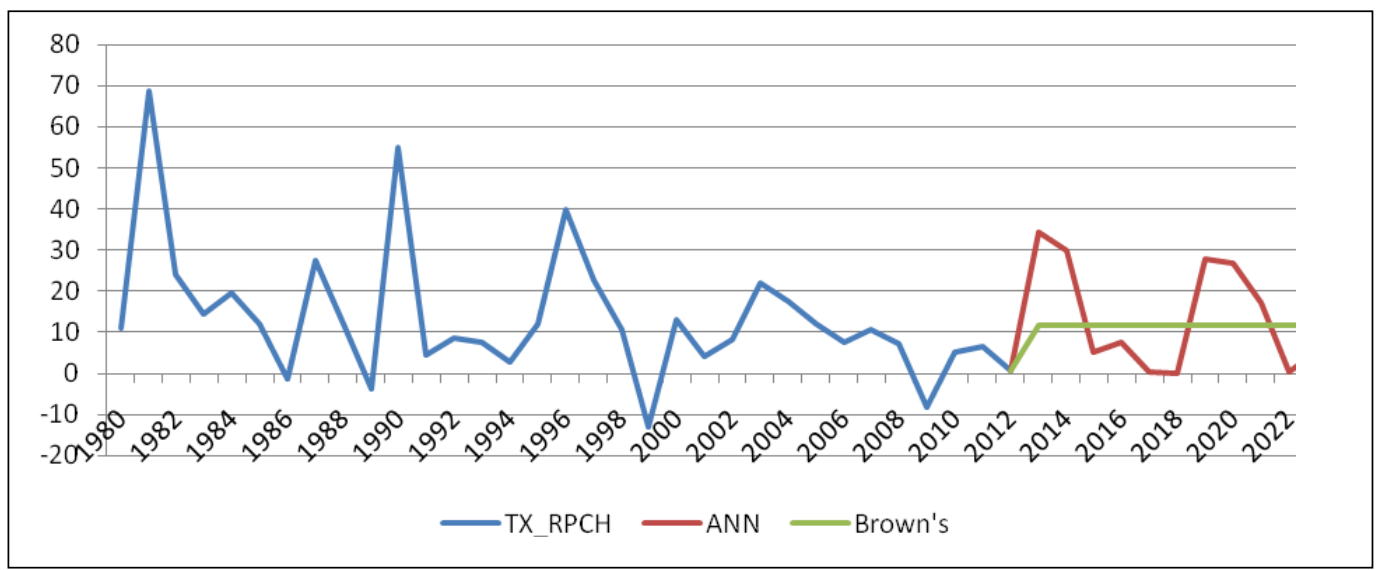

Figure 30: Comparison of "Volume of Imports of Goods and Services (TM_RPCH)" Estimations 


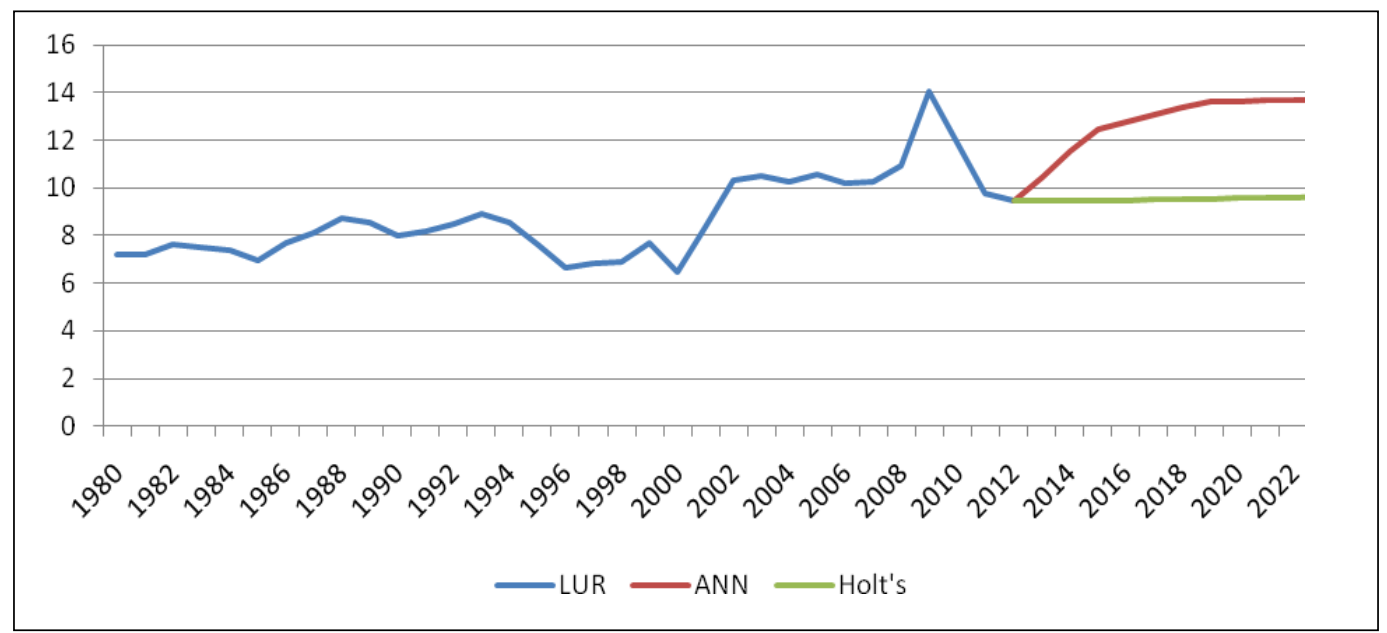

Figure 31: Comparison of "Unemployment Rate (LUR)" Estimations

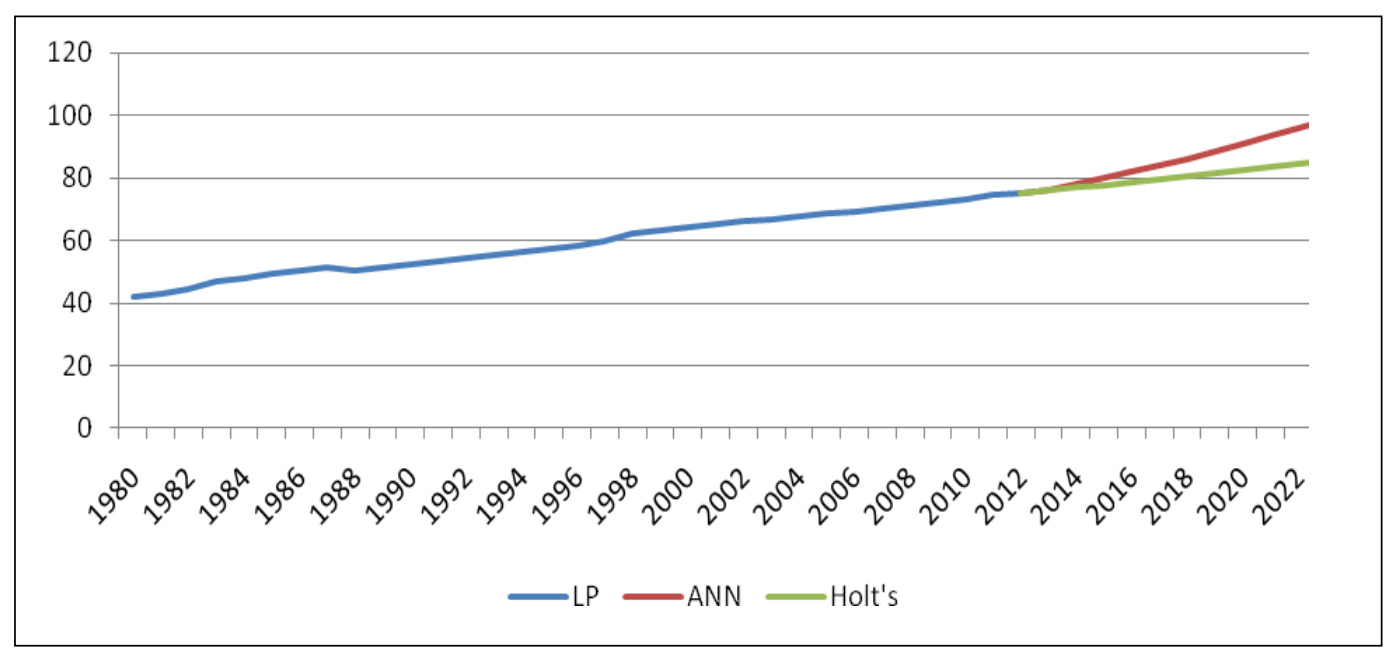

Figure 32: Comparison of "Population (LP)" Estimations

\section{Conclusion and Suggestions}

Global economic power is shifting and Turkey has the potential to be one of the biggest beneficiaries of this change. The country has the opportunity to capitalize on a growing skilled labor force and favorable climate, as well as geographical location at the crossroads of a number of wealthy regions, all of which could be used to sustain longterm economic growth and development. On the other hand, the Turkish economy has shown remarkable performance with its steady growth over last years. A sound macroeconomic strategy in combination with prudent fiscal policies and major structural reforms in effect has integrated the Turkish economy into the globalized world, while transforming the country into one of the major recipients of foreign direct investment in its region. The structural reforms, hastened by Turkey's European Union accession process, have paved the way for comprehensive changes in a number of areas. The main objectives of these efforts were to increase the role of the private sector in the Turkish 
economy, to enhance the efficiency and resiliency of the financial sector, and to place the social security system on a more solid foundation. To understand the future potential of the Turkish economy, the authors have used two different types of long-run economic growth model to forecast Turkish GDP in 2023, the centenary anniversary of the Turkish Republic. By using Holt's analysis, it is forecasted that Turkish GDP level is more than 1.14 trillion dollars and Turkey's GDP per capita (estimated value of population in 2023 is $85,530,000)$ is expected to more than US\$13,300. Whereas by using Artificial Neural Network (ANN) analysis, GDP is estimated 2.30 trillion dollars and GDP per capita (forecasted value of population in 2023 is 98,430,000) is expected to more than US $\$ 23,400$ in 2023. Our results displays that Turkey reaches 500 billion dollars of exports volume in 2023, with an average of $11.7 \%$ increase in exports annually; on the other hand volume of imports of goods and services are estimated to increase with an average of $4.5 \%$ annually. Furthermore, it is planned to reach $80 \%$ exports/imports ratio in 2023 .

Gross national savings as a percent of GDP expressed as a ratio of gross national savings and GDP. Gross national saving is gross disposable income less final consumption expenditure after taking account of an adjustment for pension funds. In addition to this, total investments as a percent of GDP expressed as a ratio of total investment and GDP. Investment or gross capital formation is measured by the total value of the gross fixed capital formation and changes in inventories and acquisitions less disposals of valuables for a unit or sector. The authors of this paper estimate the gross national savings and total investment as a percent of GDP $10.07 \%$ and $19.2 \%$ respectively in 2023 . Finally this paper forecasts that annual inflation rate will be around $5.7 \%$; annual unemployment rate will be around $9.6 \%$ (by using Holt's analysis) and will be around $13.7 \%$ (by using ANN analysis) in the centenary anniversary of the Turkish Republic.

The findings of this paper would help Turkish government and investors for creating more effective macroeconomic strategies. For the government side, future rises, falls, and turning points of the macro indicators puts into perspective the effects of government policy created to deal with them. For the investors' side, future values might increase the possibility of diligent investor in the financial market.

\section{References}

[1] Republic of Turkey Ministry of Development, Turkey's sustainable development report: Claiming the future, Ankara, June 2012.

[2] Republic of Turkey Ministry of Economy, Turkey's Export Strategy for 2023, [Online] Available from: http://www.economy.gov.tr

[3] E. Onder and O. Hasgul, Time series analysis with using Box Jenkins models and artificial neural network for forecasting number of foreign visitors, Journal of Institute of Business Administration, 20(62), (2009), 62-83.

[4] M.P. Clements, P.H. Franses and N.R. Swanson, Forecasting economic and financial time-series with non-linear models, International Journal of Forecasting, 20, (2004), 169-183.

[5] I. Kaastra and M. Boyd, Designing a neural network for forecasting financial and economics time series, Neurocomputing, 10, (1996), 215-236. 
[6] M.T. Leung, H. Daouk and A.S. Chen, Forecasting stock indices: A comparison of classification and level estimation models, International Journal of Forecasting, 16, (2000), 173-190.

[7] P. Tenti, Forecasting foreign exchange rates using recurrent neural network, Applied Artificial Intelligence, 10, (1996), 567-581.

[8] A.J. Samimi and K.D. Darabi, Forecasting government size in Iran using artificial neural network, Journal of Economics and Behavioral Studies, 3(5), (2011), 274278.

[9] M.J. Hinich, J. Foster and P. Wild, Structural change in macroeconomic time series: A complex systems perspective, Journal of Macroeconomics, 28, (2006), 136-150.

[10] H.C. Co and R. Boosarawongse, Forecasting Thailand's rice export: Statistical techniques vs. artificial neural networks, Computers and Industrial Engineering, 53, (2007), 610-627.

[11] European Union, Current Account Surpluses in the EU, European Economic Series, September 2012.

[12] N. Orhunbilge, Time Series analysis, forecasting and price index, Istanbul University School of Business Press, 1999.

[13] T.M. Mitchel, Machine Learning, McGrawHill, New York, 1997.

[14] L.S. Maciel and R. Ballini, Design a neural network for time series financial forecasting: Accuracy and robustness analysis, Instituto de Economia, Universidade Estadual de Campinas, Sao Paulo-Brasil, 2008.

[15] M.I.A. Lourakis, A brief description of the Levenberg-Marquardt Algorithm implemened by Levmar, Institute of Computer Science Foundation for Research and Technology, 2005. 